Research Paper

\title{
Electro-osmotic consolidation of soil with variable compressibility, hydraulic conductivity and electro-osmosis conductivity
}

\author{
Hui $\mathrm{Wu}^{\mathrm{a}}$, Wengang $\mathrm{Qi}^{\mathrm{b}}$, Liming $\mathrm{Hu}^{\mathrm{a}, *}$, Qingbo Wen ${ }^{\mathrm{a}}$ \\ a State Key Laboratory of Hydro-Science and Engineering, Department of Hydraulic Engineering, Tsinghua University, Beijing 100084, PR China \\ ${ }^{\mathrm{b}}$ Institute of Mechanics, Chinese Academy of Science, Beijing 100190, PR China
}

\section{A R T I C L E I N F O}

\section{Article history:}

Received 27 July 2016

Received in revised form 8 December 2016

Accepted 24 December 2016

Available online 2 January 2017

\section{Keywords:}

Electro-osmotic consolidation

Variable soil properties

Analytical solution

Numerical simulation

Excess pore water pressure

Degree of consolidation

\begin{abstract}
A B S T R A C T
In present study, the non-linear variations of soil compressibility, hydraulic and electro-osmosis conductivities were analyzed through laboratory experiments, and incorporated in a one-dimensional model. The analytical solutions for excess pore water pressure and degree of consolidation were derived, and numerical simulations were performed to verify its effectiveness. The results indicated that both the non-linear variations of hydraulic and electro-osmosis conductivities showed remarkable impacts on the excess pore water pressure and degree of consolidation, especially for soils with relative high compressibility. A further comparison with previous analytical solutions indicated that more accurate predictions could be obtained with the proposed analytical solutions.
\end{abstract}

(ㄷ) 2016 Elsevier Ltd. All rights reserved.

\section{Introduction}

Over the past few decades, there has been a substantial development of infrastructure on soft foundations worldwide. Various treatment methods have been proposed for the improvement of these soft foundations, among which electro-osmotic consolidation has proven to be a promising method, especially for soils with low permeability [1-10]. Unlike the traditional methods such as surcharge and vacuum preloading which dewater soil mass by applying a hydraulic gradient, electro-osmotic consolidation involves pairs of anodes and cathodes installed in the soil mass, through which an electrical field is applied and pore water is driven from the anode to cathode under the electrical gradient. Similar to Darcy's law, the velocity of pore water flow $v_{\mathrm{e}}$ caused by the electrical gradient can be expressed as $k_{\mathrm{e}} \times i_{\mathrm{e}}$, where $i_{\mathrm{e}}$ means electrical gradient and $k_{\mathrm{e}}$ means electro-osmosis conductivity that describes the velocity of pore water under a unit electrical gradient. For different soils, the hydraulic conductivity $k_{\mathrm{h}}$ may change from about $1 \times 10^{-8} \mathrm{~cm} / \mathrm{s}$ in clay to about $1 \times 10^{-4} \mathrm{~cm} / \mathrm{s}$ in sand, while $k_{\mathrm{e}}$ is generally in the range of $1 \times 10^{-5}$ to $1 \times 10^{-4} \mathrm{~cm}^{2}$, (V s). As a result, a small electrical gradient can balance flows caused by large hydraulic gradient in soft soil with low permeabil-

\footnotetext{
* Corresponding author.

E-mail addresses: hui-wu@mail.tsinghua.edu.cn (H. Wu), qiwengang@imech.ac. cn (W. Qi), gehu@tsinghua.edu.cn (L. Hu), wenqb@tsinghua.edu.cn (Q. Wen).
}

ity, and electro-osmosis can be much more efficient than the traditional techniques for soft soil improvement [5, 11-13].

Based on the assumption that the pore water flow resulted from hydraulic gradient and electrical gradient can be linearly superimposed, the governing equation for electro-osmotic consolidation was developed and many analytical solutions were derived based on different conditions to analyze the development of pore water pressure [14-20]. Esrig [14] developed a one-dimensional (1D) model for electro-osmotic consolidation and obtained the analytical solutions for pore water pressure and degree of consolidation considering a permeable cathode and an impermeable anode. Wan and Mitchell [15] further coupled electro-osmotic consolidation with surcharge preloading in a 1D model. Shang [16] and Xu et al. [21] proposed a $2 \mathrm{D}$ model in vertical plane to account for the combined action of electro-osmosis with surcharge preloading and vacuum preloading. Su and Wang [22] presented a 2D model in horizontal plane and derived the analytical solutions under different boundary conditions. Li et al. [17] analyzed the average pore water pressure in soils submitted to an axisymmetric electrical field. Wu and Hu [19] developed an axisymmetric model with coupled horizontal and vertical seepage and derived the analytical solution without the equal strain hypothesis. These mathematical analyses have generated significant knowledge pertaining to electro-osmotic consolidation and provided useful formulas for engineering design. However, the electrical and mechanical properties of soil are assumed constant during the derivation of these 


\begin{tabular}{|c|c|c|c|}
\hline \multicolumn{4}{|c|}{ Nomenclature } \\
\hline$a, a_{0}$ & $\begin{array}{l}\text { the coefficient of compressibility and the initial } \\
\text { coefficient of compressibility }\end{array}$ & Qult & $\begin{array}{l}\text { defined variable related to ultimate excess pore water } \\
\text { pressure }\end{array}$ \\
\hline$b$ & calculating factor related to $C_{\mathrm{c}}, M$ and $N$ & $t$ & time period \\
\hline$A$ & sectional area of the soil sample & $T_{\mathrm{v}}, T_{\mathrm{c}}, T_{\mathrm{e}}$ & time factors \\
\hline$C_{\mathrm{c}}$ & compression index & $u$ & excess pore water pressure \\
\hline$C_{\mathrm{v} 0}$ & the initial coefficient of consolidation & $u_{\mathrm{ult}}$ & ultimate excess pore water pressure \\
\hline$C_{0}$ & calculating factor for ultimate excess pore water & $U$ & degree of consolidation \\
\hline & pressure & $v_{\mathrm{z}}$ & the pore water flow in the vertical direction \\
\hline$e, e_{0}$ & void ratio and initial void ratio & $V$ & voltage \\
\hline$G_{\mathrm{n}}$ & calculating factors & $V_{0}$ & the applied voltage in the electro-osmosis test \\
\hline$H$ & height of the analytical model & W & ratio between excess pore water pressure and surcharge \\
\hline$I, J$ & calculating factors & & preloading \\
\hline$k_{\mathrm{e}}, k_{\mathrm{e} 0}$ & $\begin{array}{l}\text { electro-osmosis conductivity and initial electro-osmosis } \\
\text { conductivity }\end{array}$ & $W_{\text {ult }}$ & $\begin{array}{l}\text { ratio between ultimate excess pore water pressure and } \\
\text { surcharge preloading }\end{array}$ \\
\hline$k_{\mathrm{h}}, k_{\mathrm{h} 0}$ & $\begin{array}{l}\text { hydraulic conductivity and initial hydraulic conductiv- } \\
\text { ity }\end{array}$ & $\begin{array}{l}Z \\
\alpha, \theta\end{array}$ & $\begin{array}{l}\text { ratio between vertical position and height of the model } \\
\text { calculating factors }\end{array}$ \\
\hline $\begin{array}{l}L \\
M, N\end{array}$ & $\begin{array}{l}\text { length of the soil sample } \\
\text { factors describing the change in hydraulic and electro- }\end{array}$ & $\beta$ & $\begin{array}{l}\text { calculating factor related to surcharge preloading and } \\
\text { initial effective stress }\end{array}$ \\
\hline & $\begin{array}{l}\text { osmosis conductivities resulted from the change in void } \\
\text { ratio }\end{array}$ & $\begin{array}{l}\gamma_{\mathrm{w}} \\
\sigma^{\prime}, \sigma_{0}\end{array}$ & $\begin{array}{l}\text { unit weights of water and saturated soil } \\
\text { effective stress and initial effective stress }\end{array}$ \\
\hline$p_{0}$ & surcharge preloading & $\varepsilon$ & the weighted factor \\
\hline$q$ & volume of the discharged water due to electro-osmosis & $\xi_{n}$ & solution for $\tan (\xi / 2)=\xi / \theta$, where $n$ equals $1,2,3 \ldots \ldots$ \\
\hline$Q$ & $\begin{array}{l}\text { defined variable related to the excess pore water pres- } \\
\text { sure }\end{array}$ & $\lambda_{\mathrm{n}}$ & equals $\left(\xi_{n}^{2}+\theta^{2}\right) / 4$ \\
\hline
\end{tabular}

analytical solutions. In fact, the flow of pore water from anode to cathode during electro-osmosis causes the decrease in water content and void ratio of the treated soil, and leads to non-linear variations in soil properties such as compressibility, hydraulic conductivity and electro-osmosis conductivity [1,4,5,7,13,23-28]. Such variations would inevitably affect the development of pore water pressure during electro-osmotic consolidation, and the predictions from the existing analytical solutions with constant soil properties would be inaccurate.

Although being ignored in the analytical solutions for electroosmotic consolidation, the non-linear variations of soil compressibility and hydraulic conductivity have already been investigated in many consolidation theories [29-38]. Davis and Raymond [29] derived the analytical solution for pore water pressure with the assumption of non-linear compressibility and constant coefficient of consolidation. Poskitt [31] further coupled the relationships between void ratio $(e)$ and effective stress $\left(\sigma^{\prime}\right)$, hydraulic conductivity $\left(k_{\mathrm{h}}\right)$ into a vertical consolidation model. Lekha et al. [33] presented closed form analytical solutions for the pore water pressure and degree of consolidation for the particular cases of $e-\log \left(\sigma^{\prime}\right)$ and $e-\log \left(k_{\mathrm{h}}\right)$ responses. In these studies, the relationships of $e-\log \left(\sigma^{\prime}\right)$ and $e-\log \left(k_{\mathrm{h}}\right)$ were developed and incorporated to account for the non-linear variations of soil compressibility and permeability.

Compared to the traditional consolidation problem, electroosmotic consolidation involves not only the non-linear variations of soil compressibility and permeability but also the change in electro-osmosis conductivity. In this study, a series of experiments were performed to investigate the variations of hydraulic and electro-osmosis conductivities during electro-osmotic consolidation. Afterwards, the relationships between the hydraulic conductivity, electro-osmosis conductivity and void ratio were developed based on the experiment results, and further incorporated into a 1D model for electro-osmotic consolidation together with the conventional $e-\log \left(\sigma^{\prime}\right)$ response. The analytical solutions for excess pore water pressure and degree of consolidation were derived and compared with that from Wan and Mitchell (1976) to investigate the effects of the non-linear variations of soil properties.

\section{Experimental study}

A kaolinite from Jiangsu Province, China was used to conduct permeability and electro-osmosis tests. The basic properties and chemical composition of the kaolinite were listed in Table 1 . The as-received kaolinite was first oven dried, then mixed with water at a water content of $10 \%$ and compacted into the test devices in five layers according to the pre-determined void ratio in the range of 1.373-0.919, and finally saturated under a vacuum.

The hydraulic conductivities of the kaolinite samples were monitored with the falling head permeability test, and the electro-osmosis conductivities were measured using a selfdesigned apparatus $90 \mathrm{~mm}$ in diameter and $400 \mathrm{~mm}$ in height as shown in Fig. 1. The anode platen was placed on the bottom of the kaolinite sample, while the porous cathode platen on the top, allowing the drainage of pore water into a graduated cylinder. In order to eliminate the effect of hydraulic gradient, the bottom of the kaolinite sample was connected to a water reservoir with a

Table 1

Geotechnical properties and chemical composition of the kaolinite.

\begin{tabular}{ll}
\hline Geotechnical property & Value \\
\hline Initial water content, $w_{0}(\%)$ & 1.31 \\
Liquid limit, $w_{\mathrm{L}}(\%)$ & 58 \\
Plastic limit, $w_{\mathrm{p}}(\%)$ & 23 \\
Plasticity index, $I_{\mathrm{p}}(\%)$ & 35 \\
Specific gravity, $G_{\mathrm{s}}$ & 2.61 \\
$\mathrm{Chemical} \mathrm{composition}_{\mathrm{SiO}_{2}}$ & 2.0 \\
$\mathrm{Al}_{2} \mathrm{O}_{3}$ & 50 \\
$\mathrm{Fe}_{2} \mathrm{O}_{3}$ & 35 \\
$\mathrm{~K}_{2} \mathrm{O}+\mathrm{Na}_{2} \mathrm{O}$ & 3.2 \\
\hline
\end{tabular}




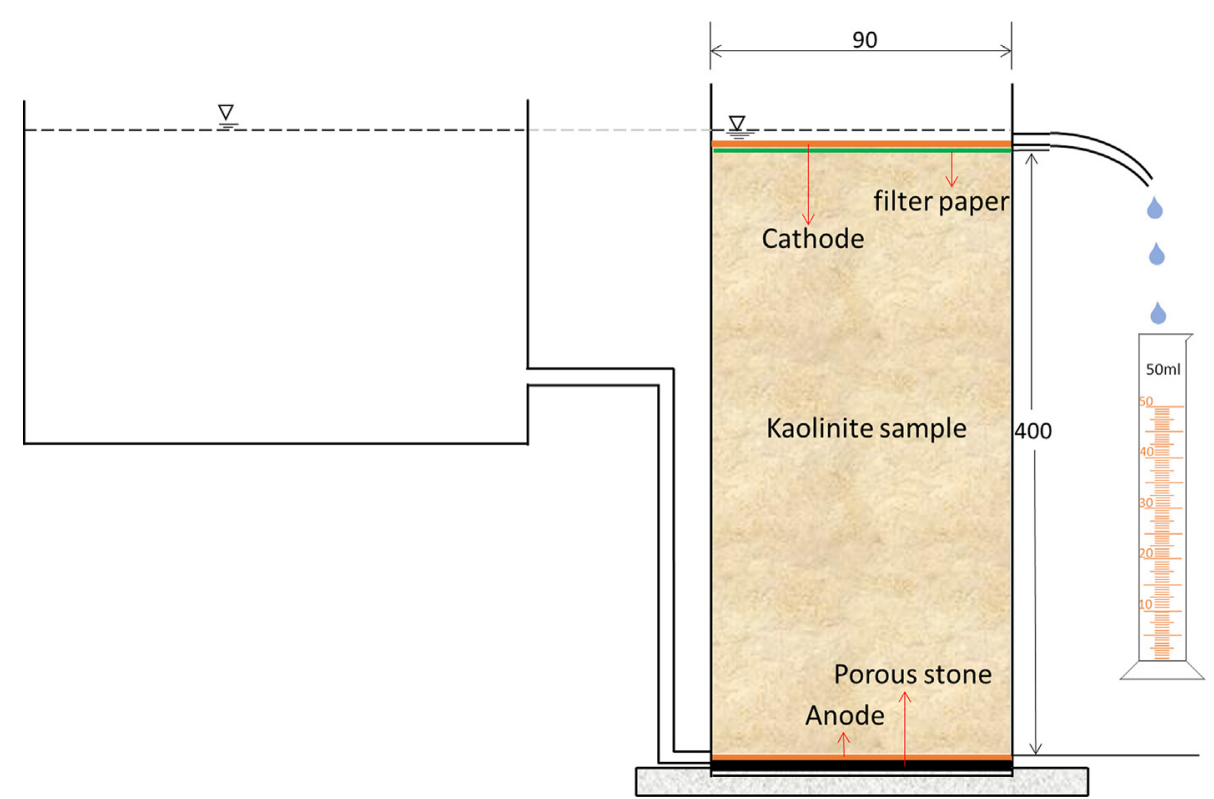

Fig. 1. One-dimensional apparatus for electro-osmosis experiment (length unit: mm).

water level as high as the top surface of the kaolinite sample. After the saturation of the kaolinite sample and the connection to the water blank, the whole system was allowed to stand for at least 2 days to reach equilibrium. Afterwards, an electrical field was applied and the electro-osmosis conductivity was calculated with the following equation,

$k_{\mathrm{e}}=\frac{q \cdot L}{A \cdot t \cdot V_{0}}$

where $q$ is the volume of the discharged water due to electroosmosis; $L$ and $A$ are the length and cross sectional area of the soil sample; $t$ is time period; $V_{0}$ is the applied voltage.

Fig. 2 shows the hydraulic and electro-osmosis conductivities of the kaolinite. With the decrease in void ratio, both $k_{\mathrm{h}}$ and $k_{\mathrm{e}}$ decrease, and their relationships with void ratio can be expressed as following,

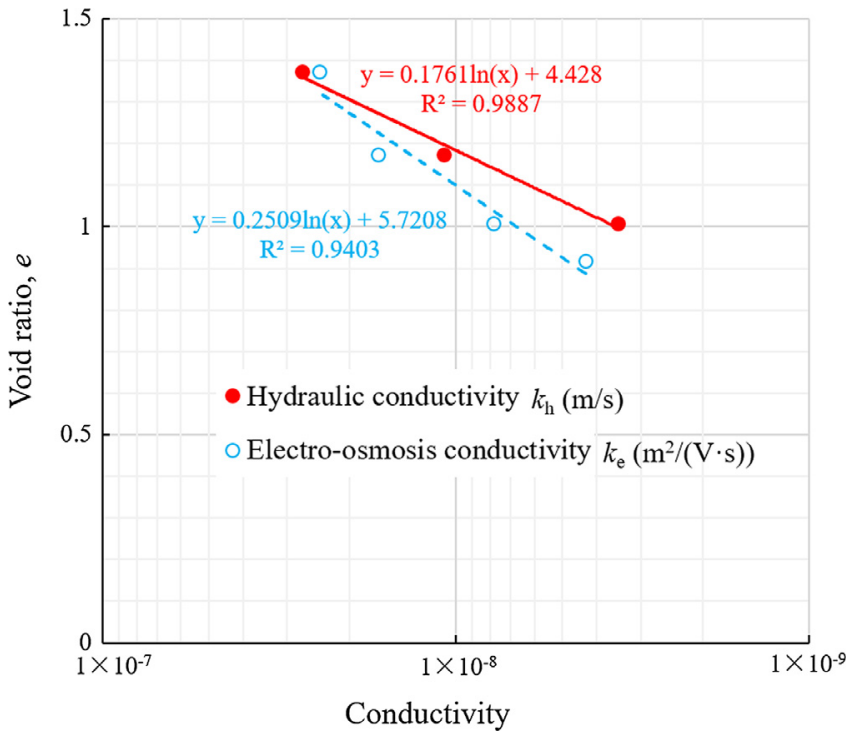

Fig. 2. Relationships between void ratio and hydraulic conductivity and electroosmosis conductivity.

$$
\begin{aligned}
e & =4.428+0.1761 \ln \left(k_{\mathrm{h}}\right) \\
& =1.373+0.4055 \times \log \left[k_{\mathrm{h}} /\left(2.92 \times 10^{-8} \mathrm{~m} / \mathrm{s}\right)\right] \\
e & =5.7208+0.2509 \ln \left(k_{\mathrm{e}}\right) \\
& =1.373+0.5777 \times \log \left[k_{\mathrm{e}} /\left(2.98 \times 10^{-8} \mathrm{~m}^{2} /(\mathrm{V} \mathrm{s})\right)\right]
\end{aligned}
$$

Previous studies have investigated the variation of void ratio during the consolidation process [29-31,33], and the results indicated that the relationship between void ratio and effective stress could be written as,

$e=e_{0}-C_{\mathrm{c}} \cdot \log \left(\sigma^{\prime} / \sigma_{0}\right)$

in which $e_{0}$ is initial void ratio, $\sigma_{0}$ is initial effective stress, and $C_{\mathrm{c}}$ is the compression index.

Similar to Eq. (4), the general form for $e-\log \left(k_{\mathrm{h}}\right)$ and $e-\log \left(k_{\mathrm{e}}\right)$ responses can be obtained according to Eqs. (2) and (3),

$e=e_{0}+M \cdot \log \left(k_{\mathrm{h}} / k_{\mathrm{h} 0}\right)$

$e=e_{0}+N \cdot \log \left(k_{\mathrm{e}} / k_{\mathrm{e} 0}\right)$

in which $k_{\mathrm{h} 0}$ and $k_{\mathrm{e} 0}$ are initial hydraulic and electro-osmosis conductivities corresponding to $e_{0} ; M$ and $N$ are factors that reflect the changes in hydraulic and electro-osmosis conductivities resulted from the change in void ratio.

Eqs. (4)-(6) together describe the non-linear variations of soil compressibility, hydraulic conductivity and electro-osmosis conductivity during the consolidation process.

\section{Theoretical analysis}

Similar to previous studies, a schematic diagram of the 1D model for electro-osmotic consolidation is developed as shown in Fig. 3, with the anode on the bottom and cathode on the top $[1,12-13,18]$. The bottom boundary is impermeable and the top boundary is permeable. A surcharge preloading $p_{0}$ is applied on the top boundary of the model. The following assumptions are made to develop the analytical model for electro-osmotic consolidation.

(1) The soil is homogeneous and fully saturated, and the pore water and soil grain are incompressible. 


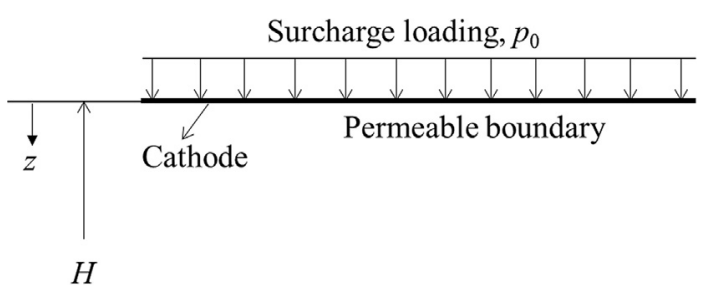

Anode

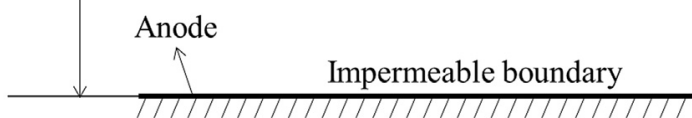

Fig. 3. Diagram of the one-dimensional analytical model for electro-osmotic consolidation.

(2) Both the drainage of pore water and the compression of soil layer occur in the vertical direction.

(3) The velocity of pore water flow due to electro-osmosis is directly proportional to the electrical gradient, and can be linearly superimposed with that due to hydraulic gradient.

(4) The relationships between $e$ and $\sigma^{\prime}, k_{\mathrm{h}}$ and $k_{\mathrm{e}}$ in Eqs. (4)-(6) hold.

(5) The loading is instantaneously applied, and the small strain hypothesis is adopted.

(6) The pore water flow caused by thermal gradient and chemical concentration gradient is neglected.

The combined pore water flow during electro-osmotic consolidation can be described as following [7, 14, 15, 19],

$v_{\mathrm{z}}=-\frac{k_{\mathrm{h}}}{\gamma_{\mathrm{w}}} \frac{\partial u}{\partial z}-k_{\mathrm{e}} \frac{\partial V}{\partial z}$

where $v_{z}$ is the pore water flow in the vertical direction; $\gamma_{w}$ is the unit weight of water; $u$ is excess pore water pressure; $V$ is the voltage.

According to the conservation of pore water in a saturated soilwater system,

$\frac{\partial v_{z}}{\partial z}=\frac{-1}{1+e_{0}} \frac{\partial e}{\partial t}=\frac{1}{1+e_{0}}\left(\frac{\partial e}{\partial \sigma^{\prime}}\right) \frac{\partial u}{\partial t}$

Substituting Eq. (7) into Eq. (8), and making use of the substitutions $W=u / p 0$ and $Z=z / H$ ( $H$ is the height of the model), the following equation can be obtained,

$\frac{1}{H^{2}} \frac{\partial}{\partial Z}\left(\frac{k_{\mathrm{h}} \cdot p_{0}}{\gamma_{\mathrm{w}}} \frac{\partial W}{\partial Z}+k_{\mathrm{e}} \frac{\partial V}{\partial Z}\right)=\frac{p_{0}}{1+e_{0}}\left(\frac{\partial e}{\partial \sigma^{\prime}}\right) \frac{-\partial W}{\partial t}=\frac{p_{0}}{1+e_{0}} a \frac{\partial W}{\partial t}$

where $a$ denotes the coefficient of compressibility. Further simplifying Eq. (9) to,

$$
\begin{aligned}
\frac{\partial W}{\partial t} & =\frac{k_{\mathrm{h} 0}\left(1+e_{0}\right)}{\gamma_{\mathrm{w}} H^{2} a} \cdot \frac{\partial}{\partial Z}\left(\frac{k_{\mathrm{h}}}{k_{\mathrm{h} 0}} \frac{\partial W}{\partial Z}+\frac{k_{\mathrm{e}} \gamma_{\mathrm{w}}}{k_{\mathrm{h} 0} p_{0}} \frac{\partial V}{\partial Z}\right) \\
& \Rightarrow \frac{\partial W}{\partial T_{\mathrm{v}}}=\frac{a_{0}}{a} \cdot \frac{\partial}{\partial Z}\left(\frac{k_{\mathrm{h}}}{k_{\mathrm{h} 0}} \frac{\partial W}{\partial Z}+\frac{k_{\mathrm{e}} \gamma_{\mathrm{w}}}{k_{\mathrm{h} 0} p_{0}} \frac{\partial V}{\partial Z}\right)
\end{aligned}
$$

where $a_{0}$ is the initial coefficient of compressibility; $T_{\mathrm{V}}$ is the time factor and equals to $C_{\mathrm{v} 0} \cdot t / H^{2} ; C_{\mathrm{v} 0}$ is the initial coefficient of consolidation.

According to Lekha et al. [33], the non-linear variations of soil compressibility, hydraulic conductivity and electro-osmosis conductivity can be rewritten as,

$$
\begin{aligned}
\frac{a_{0}}{a} & =\frac{\sigma^{\prime}}{\sigma_{0}}=\frac{\sigma_{0}+p_{0}-W \cdot p_{0}}{\sigma_{0}}=\left(1+\frac{p_{0}}{\sigma_{0}}\right) \cdot\left(1-\frac{W \frac{p_{0}}{\sigma_{0}}}{1+\frac{p_{0}}{\sigma_{0}}}\right) \\
& =\left(1+\frac{p_{0}}{\sigma_{0}}\right) \cdot(1-\beta W)
\end{aligned}
$$

$$
\begin{aligned}
& \frac{k_{\mathrm{h}}}{k_{\mathrm{h} 0}}=\left(\frac{\sigma^{\prime}}{\sigma_{0}}\right)^{-C_{\mathrm{c}} / M}=\left(\frac{a_{0}}{a}\right)^{-C_{\mathrm{c}} / M}=\left[\left(1+\frac{p_{0}}{\sigma_{0}}\right) \cdot(1-\beta W)\right]^{-C_{\mathrm{c}} / M} \\
& \frac{k_{\mathrm{e}}}{k_{\mathrm{e} 0}}=\left(\frac{\sigma^{\prime}}{\sigma_{0}}\right)^{-C_{\mathrm{c}} / N}=\left(\frac{a_{0}}{a}\right)^{-C_{\mathrm{c}} / N}=\left[\left(1+\frac{p_{0}}{\sigma_{0}}\right) \cdot(1-\beta W)\right]^{-C_{\mathrm{c}} / N}
\end{aligned}
$$

where $\beta$ is defined as $\left(p_{0} / \sigma_{0}\right) /\left(1+p_{0} / \sigma_{0}\right)$.

Substituting Eqs. (11)-(13) into Eq. (10),

$$
\begin{aligned}
\frac{\partial W}{\partial T_{\mathrm{v}}}= & \left(1+\frac{p_{0}}{\sigma_{0}}\right)(1-\beta W) \cdot \frac{\partial}{\partial Z}\left\{\left[\left(1+\frac{p_{0}}{\sigma_{0}}\right)(1-\beta W)\right]^{-C_{\mathrm{c}} / M} \frac{\partial W}{\partial Z}\right\} \\
& +\left(1+\frac{p_{0}}{\sigma_{0}}\right)(1-\beta W) \\
& \cdot \frac{\partial}{\partial Z}\left\{\left[\left(1+\frac{p_{0}}{\sigma_{0}}\right)(1-\beta W)\right]^{-C_{\mathrm{c}} / N} \cdot \frac{\partial V}{\partial Z} \cdot \frac{k_{\mathrm{e} 0} \gamma_{\mathrm{w}}}{k_{\mathrm{h} 0} p_{0}}\right\}
\end{aligned}
$$

Defining a new parameter $Q$ as,

$$
\begin{aligned}
Q= & (1-\beta W)^{1+C_{\mathrm{c}} / N-C_{\mathrm{c}} / M}-\beta \cdot\left(1+\frac{C_{\mathrm{c}}}{N}-\frac{C_{\mathrm{c}}}{M}\right) \cdot\left(1+\frac{p_{0}}{\sigma_{0}}\right)^{C_{\mathrm{c}} / M-C_{\mathrm{c}} / N} \\
& \cdot \frac{k_{\mathrm{e} 0} \gamma_{\mathrm{w}}}{k_{\mathrm{h} 0} p_{0}} \cdot \frac{\partial V}{\partial Z} \cdot Z=(1-\beta W)^{1+C_{\mathrm{c}} / N-C_{\mathrm{c}} / M}-C_{0} \cdot Z
\end{aligned}
$$

in which $\quad C_{0}=\beta \cdot\left(1+C_{\mathrm{c}} / N-C_{\mathrm{c}} / M\right) \cdot\left(1+p_{0} / \sigma_{0}\right)^{C \mathrm{c} / M-C \mathrm{C} / N} \cdot k_{\mathrm{e} 0} \cdot \gamma_{\mathrm{w}} /$ $k_{\mathrm{ho}} / p_{0} \cdot \partial V / \partial Z$.

Then Eq. (14) is simplified to,

$$
\begin{aligned}
\frac{\partial Q}{\partial T_{\mathrm{v}}}= & \left(Q+C_{0} \cdot Z\right) \cdot\left(1+\frac{p_{0}}{\sigma_{0}}\right)^{1-C_{\mathrm{c}} / M} \cdot \frac{\partial}{\partial Z}\left[(1-\beta W)^{-C_{\mathrm{c}} / N} \frac{\partial Q}{\partial Z}\right] \\
\Rightarrow & \frac{\partial Q}{\partial T_{\mathrm{c}}}=\left(Q+C_{0} \cdot Z\right) \cdot \frac{\partial}{\partial Z}\left[(1-\beta W)^{-C_{\mathrm{c}} / N} \frac{\partial Q}{\partial Z}\right] \\
= & \left(Q+C_{0} \cdot Z\right) \cdot \frac{\partial}{\partial Z}\left[\left(Q+C_{0} \cdot Z\right)^{b} \frac{\partial Q}{\partial Z}\right] \\
\Rightarrow & \frac{\partial Q}{\partial T_{\mathrm{c}}}=\left(Q+C_{0} \cdot Z\right)^{b+1} \frac{\partial^{2} Q}{\partial Z^{2}}+\left(Q+C_{0} \cdot Z\right)^{b} \cdot b \cdot \frac{\partial Q}{\partial Z} \cdot \frac{\partial Q}{\partial Z} \\
& +\left(Q+C_{0} \cdot Z\right)^{b} \cdot b \cdot C_{0} \cdot \frac{\partial Q}{\partial Z}
\end{aligned}
$$

where $T_{\mathrm{c}}=T_{\mathrm{v}} \cdot\left(1+p_{0} / \sigma_{0}\right)^{(1-C \mathrm{c} / M)} ; b=\left(-C_{\mathrm{c}} / N\right) /\left(1+C_{\mathrm{c}} / N-C_{\mathrm{c}} / M\right)$.

According to the description of the model (Fig. 3), the boundary and initial conditions of the problem are,

$$
\left\{\begin{array}{l}
Z=0, u=0 \Rightarrow Q=1 \\
Z=1, \frac{k_{\mathrm{h}}}{\gamma_{\mathrm{w}}} \frac{\partial u}{\partial z}+k_{\mathrm{e}} \frac{\partial V}{\partial z}=0 \Rightarrow \frac{\partial Q}{\partial Z}=0 \\
t=0, u=p_{0} \Rightarrow Q=(1-\beta)^{1+C_{\mathrm{c}} / N-C_{\mathrm{c}} / M}-C_{0} \cdot Z
\end{array}\right.
$$

Eq. (16) is non-linear in $Q$ and therefore does not have a general solution with the boundary and initial conditions in Eq. (17). In order to solve $Q$ from Eq. (16), the coefficient terms on the right hand side of Eq. (16) are replaced by their weighted average value. Specifically, when $t=0, Q=\left(1+p_{0} / \sigma_{0}\right)^{(C \mathrm{Cc} / M-C \mathrm{Cc} / N-1)}-C_{0} \cdot Z$; when $t$ tends to infinity, the pore water flow caused by electro-osmosis from the anode to cathode is exactly balanced by that caused by hydraulic gradient from the cathode to anode, and the following equation can be obtained,

$\frac{k_{\mathrm{h}}}{\gamma_{\mathrm{w}}} \cdot \frac{\partial u}{\partial z}+k_{\mathrm{e}} \cdot \frac{\partial V}{\partial z}=0 \Rightarrow \frac{\partial W}{\partial Z}+\frac{k_{\mathrm{e}} \cdot \gamma_{\mathrm{w}}}{k_{\mathrm{h}} \cdot p_{0}} \cdot \frac{\partial V}{\partial Z}=0$

Therefore,

$$
\begin{aligned}
& \frac{\partial Q}{\partial Z}=-\beta \cdot\left(1+\frac{C_{\mathrm{c}}}{N}-\frac{C_{\mathrm{c}}}{M}\right) \cdot(1-\beta W)^{C_{\mathrm{c}} / N-C_{\mathrm{c}} / M} \cdot \frac{\partial W}{\partial Z}-C_{0} \\
& =\beta \cdot\left(1+\frac{C_{\mathrm{c}}}{N}-\frac{C_{\mathrm{c}}}{M}\right) \cdot\left(1+\frac{p_{0}}{\sigma_{0}}\right)^{C_{\mathrm{c}} / M-C_{\mathrm{c}} / N} \cdot \frac{k_{\mathrm{e} 0} \gamma_{\mathrm{w}}}{k_{\mathrm{h} 0} p_{0}} \frac{\partial V}{\partial Z}-C_{0}=0
\end{aligned}
$$


Considering the top boundary condition, $Q$ equals 1 when $t$ tends to infinity. A weighted average value for $\left(Q+C_{0} Z\right)$ is then assumed as following,

$\left(Q+C_{0} Z\right)_{\mathrm{av}}=\varepsilon \cdot\left(1+\frac{p_{0}}{\sigma_{0}}\right)^{C_{\mathrm{c}} / M-C_{\mathrm{c}} / N-1}+(1-\varepsilon) \cdot\left(1+0.5 C_{0}\right)$

where $\varepsilon$ is the weighted factor. Substituting Eq. (20) into Eq. (16),

$$
\begin{aligned}
& \frac{\partial Q}{\partial T_{\mathrm{e}}}=\frac{\partial^{2} Q}{\partial Z^{2}}+\alpha \cdot \frac{\partial Q}{\partial Z} \cdot \frac{\partial Q}{\partial Z}+\theta \cdot \frac{\partial Q}{\partial Z} \\
& T_{\mathrm{e}}=\left[\varepsilon \cdot\left(1+\frac{p_{0}}{\sigma_{0}}\right)^{C_{\mathrm{c}} / M-C_{\mathrm{c}} / N-1}+(1-\varepsilon) \cdot\left(1+0.5 C_{0}\right)\right]^{b+1} \cdot T_{\mathrm{c}} \\
& \alpha=\frac{b}{\varepsilon \cdot\left(1+\frac{p_{0}}{\sigma_{0}}\right)^{C_{\mathrm{c}} / M-C_{\mathrm{c}} / N-1}+(1-\varepsilon) \cdot\left(1+0.5 C_{0}\right)}, \theta=C_{0} \cdot \alpha
\end{aligned}
$$

Combining Eq. (21) with Eq. (17), $Q$ and $u$ can be solved (details are given in Appendix A),

$Q=\frac{1}{\alpha} \ln \left[\sum_{n=1}^{\infty} G_{n} e^{-\lambda_{n} T_{e}} \cdot e^{-\frac{1}{2} \theta Z} \cdot \sin \left(\frac{1}{2} \xi_{n} Z\right)+1\right]+1$

$u=\frac{p_{0}}{\beta}-\frac{p_{0}}{\beta} \cdot\left\{\frac{1}{\alpha} \ln \left[\sum_{n=1}^{\infty} G_{n} e^{-\lambda_{n} T_{\mathrm{e}}} \cdot e^{-\frac{1}{2} \theta Z} \cdot \sin \left(\frac{1}{2} \xi_{n} Z\right)+1\right]+1+C_{0} Z\right\}^{1 /\left(1+C_{\mathrm{c}} / N-C_{\mathrm{c}} / M\right)}$

where $\xi_{n}$ is a solution for $\tan (\xi / 2)=\xi / \theta ; \lambda_{n}=\left(\xi_{n}{ }^{2}+\theta^{2}\right) / 4 ; G_{n}$ can be expressed as,

$$
\begin{array}{r}
G_{n}=\frac{I \cdot \frac{2}{\xi_{n}} \cdot\left(1-e^{J} \cdot \frac{\theta}{\sqrt{\theta^{2}+\xi_{n}^{2}}}+J \cdot e^{J} \cdot \frac{2}{\xi_{n}} \cdot \frac{\xi_{n}}{\sqrt{\theta^{2}+\xi_{n}^{2}}}\right)}{\left(1+J^{2} \cdot \frac{4}{\xi_{n}^{2}}\right) \cdot\left(\frac{1}{2}-\frac{\theta}{\theta^{2}+\xi_{n}^{2}}\right)} \\
-\frac{\frac{2}{\xi_{n}}\left(1-e^{\frac{1}{2} \theta} \cdot \frac{\theta}{\sqrt{\theta^{2}+\xi_{n}^{2}}}+\frac{1}{2} \theta \cdot e^{\frac{1}{2} \theta} \cdot \frac{2}{\xi_{n}} \cdot \frac{\xi_{n}}{\sqrt{\theta^{2}+\xi_{n}^{2}}}\right)}{\left(1+\frac{\theta^{2}}{\xi_{n}^{2}}\right) \cdot\left(\frac{1}{2}-\frac{\theta}{\theta^{2}+\xi_{n}^{2}}\right)} \\
I=e^{\alpha\left[\left(1+\frac{p_{0}}{\sigma_{0}}\right)^{C_{\mathrm{C}} / M-C_{\mathrm{C}} / N-1}-1\right], \quad J=\frac{1}{2} \theta-\alpha C_{0}}
\end{array}
$$

The degree of consolidation $U$ can be calculated as,
Table 2

Basic parameters for electro-osmotic consolidation in the analytical model.

\begin{tabular}{ll}
\hline Parameter & Value \\
\hline Unit weight of water, $\gamma_{\text {sat }}\left(\mathrm{kN} / \mathrm{m}^{3}\right)$ & 10 \\
Initial hydraulic conductivity, $k_{\mathrm{h} 0}(\mathrm{~m} / \mathrm{s})$ & $2 \times 10^{-8}$ \\
Initial electro-osmosis conductivity, $k_{\mathrm{e} 0}\left(\mathrm{~m}^{2} \mathrm{~s}^{-1} \mathrm{~V}^{-1}\right)$ & $2 \times 10^{-9}$ \\
Surcharge preloading, $p_{0}(\mathrm{kPa})$ & 50 \\
Initial effective stress, $\sigma_{0}(\mathrm{kPa})$ & 10 \\
Initial void ratio, $e_{0}$ & 2.0 \\
Initial coefficient of compressibility, $a_{0}\left(\mathrm{MPa}^{-1}\right)$ & 8.7 \\
Compressibility index, $C_{\mathrm{c}}$ & 0.2 \\
$M$ & 2 \\
$N$ & 8 \\
Applied voltage, $V_{0}(\mathrm{~V})$ & 40 \\
Model height, $H(\mathrm{~m})$ & 1 \\
\hline
\end{tabular}

Eq. (17) and the non-linear variations of soil properties in Eqs. (4)-(6). In addition, the analytical solution with constant soil properties from Wan and Mitchell [15] is compared with the analytical solution proposed in this study to analyze the effect of the non-linear variations of soil properties. The basic soil parameters used in the analytical solutions and numerical models are listed in Table 2.

\subsection{Effect of the weighted factor}

In order to solve $u$ from Eq. (16), a weighted average value for $\left(Q+C_{0} \cdot Z\right)$ is introduced in Eq. (20). In fact, the term $Q+C_{0} \cdot Z$ can be expressed as following,

$Q+C_{0} \cdot Z=(1-\beta W)^{1+C_{c} / N-C_{c} / M}$

As afore analyzed, when $t=0, u=p_{0}$, and $Q+C_{0} \cdot Z$ $=\left(1+p_{0} / \sigma_{0}\right)^{(C \mathrm{Cc} / M-C \mathrm{Cc} / N-1)}$, and when $t$ approaches infinity, $Q$ $+C_{0} \cdot Z=1+C_{0} \cdot Z$. Note that the value of the term $\left(Q+C_{0} \cdot Z\right)$ is uniform along the vertical direction at the beginning, and linearly increases from 1 at $Z=0$ to $1+C_{0}$ at $Z=1$ at the end of electro-osmosis. The average value for this term is $\left(1+p_{0} / \sigma_{0}\right)^{(C c / M-C c / N-1)}$ and $1+0.5 C_{0}$ at the beginning and end of electro-osmosis respectively, and $\left(Q+C_{0} \cdot Z\right)_{\text {av }}$ in Eq. (20) is actually a weighted average value along the time scale. The weighted factor $\varepsilon$ was assumed to be 0.5 in the consolidation theory from Lekha et al. [33], however, most of

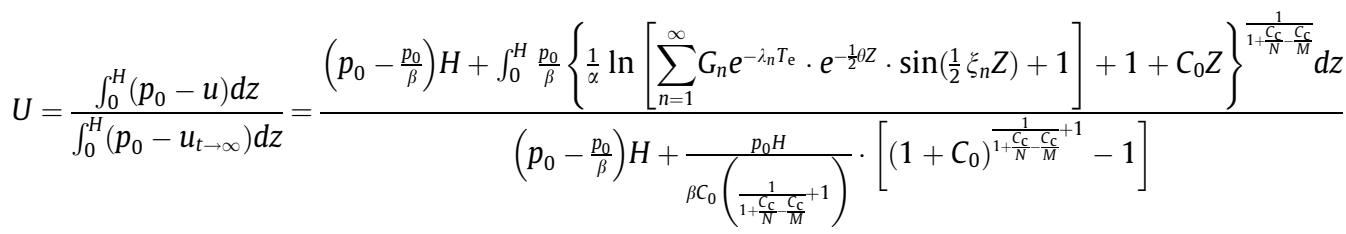

The integral in Eq. (25) is highly related to the value of $1 /\left(1+C_{\mathrm{c}} \mid\right.$ $\left.N-C_{\mathrm{c}} / M\right)$ and cannot be expressed by elementary functions. Therefore, the Newton-Cotes formula is used to estimate its value.

\section{Discussion}

Due to the assumption about the coefficient terms in Eq. (16), the solution in Eq. (23) for the excess pore water pressure is actually not accurate. In order to examine the effectiveness of the solution, a numerical model is developed based on the governing equation in Eq. (10), the boundary and initial conditions in previous studies about electro-osmosis indicated that the variation of pore water pressure was highly nonlinear, therefore a weighted factor of 0.5 may not be appropriate for electro-osmotic consolidation in this study.

In order to study the change in $\left(Q+C_{0} \cdot Z\right)$ during electro-osmotic consolidation and evaluate the value of $\varepsilon$, numerical simulations are performed considering the non-linear variations of soil properties (Eqs. (4)-(6)), and sensitivity analysis is conducted to study the effect of different factors (initial hydraulic and electro-osmosis conductivities, voltage, surcharge preloading, initial effective stress, compression index, $M$ and $N$ ) by changing one parameter and keeping others remain as they are in Table 2 in the numerical 


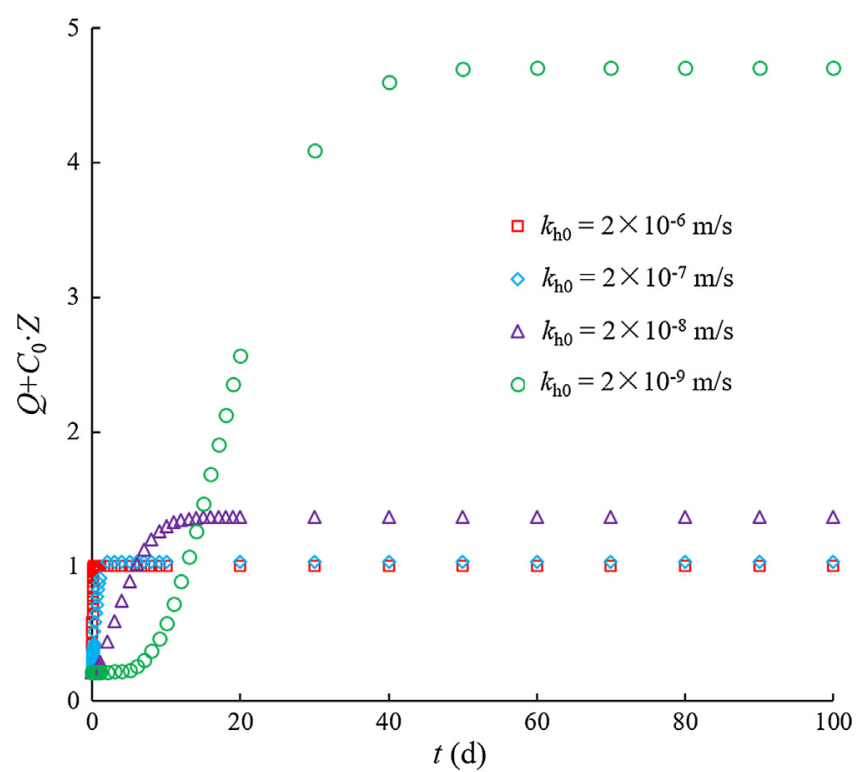

Fig. 4. Development of $\left(Q+C_{0} \cdot Z\right)$ for varied hydraulic conductivity.
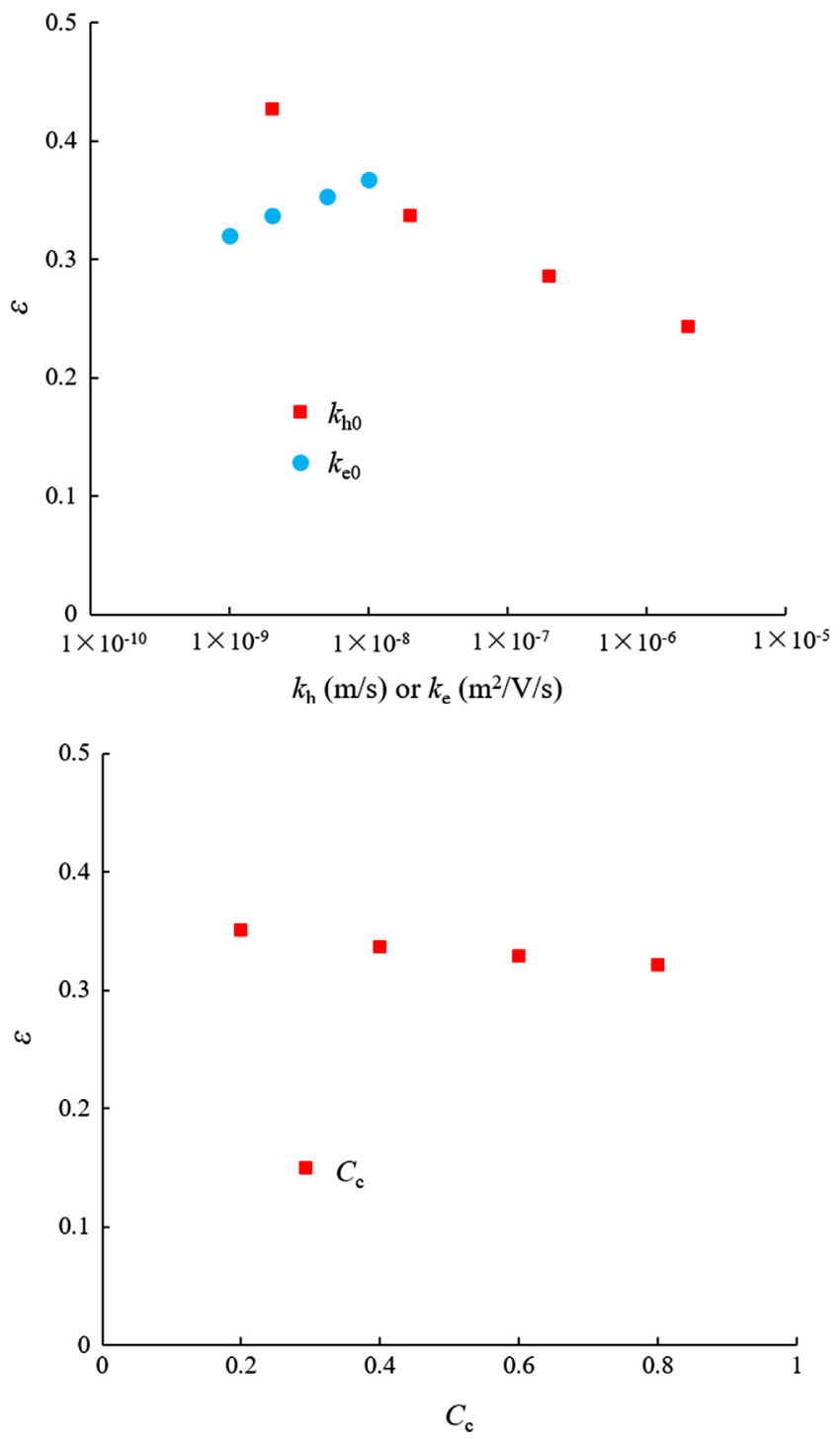

simulations. Fig. 4 shows the development of the values of $\left(Q+C_{0} \cdot Z\right)$ with different initial hydraulic conductivities. Since the value of $\left(Q+C_{0} \cdot Z\right)$ increases rapidly at the beginning and gradually becomes stable, the value of $\varepsilon$ should be smaller than 0.5 according to the area equivalent principle. Taking the time for $U=99.0 \%$ as the end of electro-osmotic consolidation, the weighted factor $\varepsilon$ can be estimated as $0.24,0.29,0.34$, and 0.43 for $k_{\mathrm{h} 0}=2 \times 10^{-6}$, $2 \times 10^{-7}, 2 \times 10^{-8}$, and $2 \times 10^{-9} \mathrm{~m} / \mathrm{s}$ respectively. Fig. 5 further displays the estimated weighted factor under different soil parameters. The value of $\varepsilon$ increases with the increase in $k_{\mathrm{e} 0}$ and the decrease in $k_{\mathrm{h} 0}$, and the impacts of other factors are smaller than that of $k_{\mathrm{h} 0}$ and $k_{\mathrm{e} 0}$. According to Fig. 5, the value of $\varepsilon$ is 0.33 when soil parameters listed in Table 2 are adopted. For a soil with different initial hydraulic and electro-osmosis conductivities, the value of $\varepsilon$ can be adjusted according to Fig. 5. It is worth noting that for most natural clays, $k_{\mathrm{e} 0}$ is generally in the range of $1 \times 10^{-8} \sim 1 \times 10^{-9} \mathrm{~m}^{2} /(\mathrm{V} \mathrm{s})$, therefore the effect of $k_{\mathrm{e} 0}$ is small and the value of $\varepsilon$ is mainly dominated by $k_{\mathrm{h} 0}$. For example, for a clay with relative large $k_{\mathrm{ho}}\left(1 \times 10^{-7} \mathrm{~m} / \mathrm{s}\right)$, the value of $\varepsilon$ is assessed to be about 0.30 , while for a clay with relative small $k_{\mathrm{h} 0}\left(1 \times 10^{-9} \mathrm{~m} / \mathrm{s}\right)$, the value of $\varepsilon$ is about 0.45 . Therefore, for a natural clay submitted to electro-osmosis, the value of $\varepsilon$ is generally in
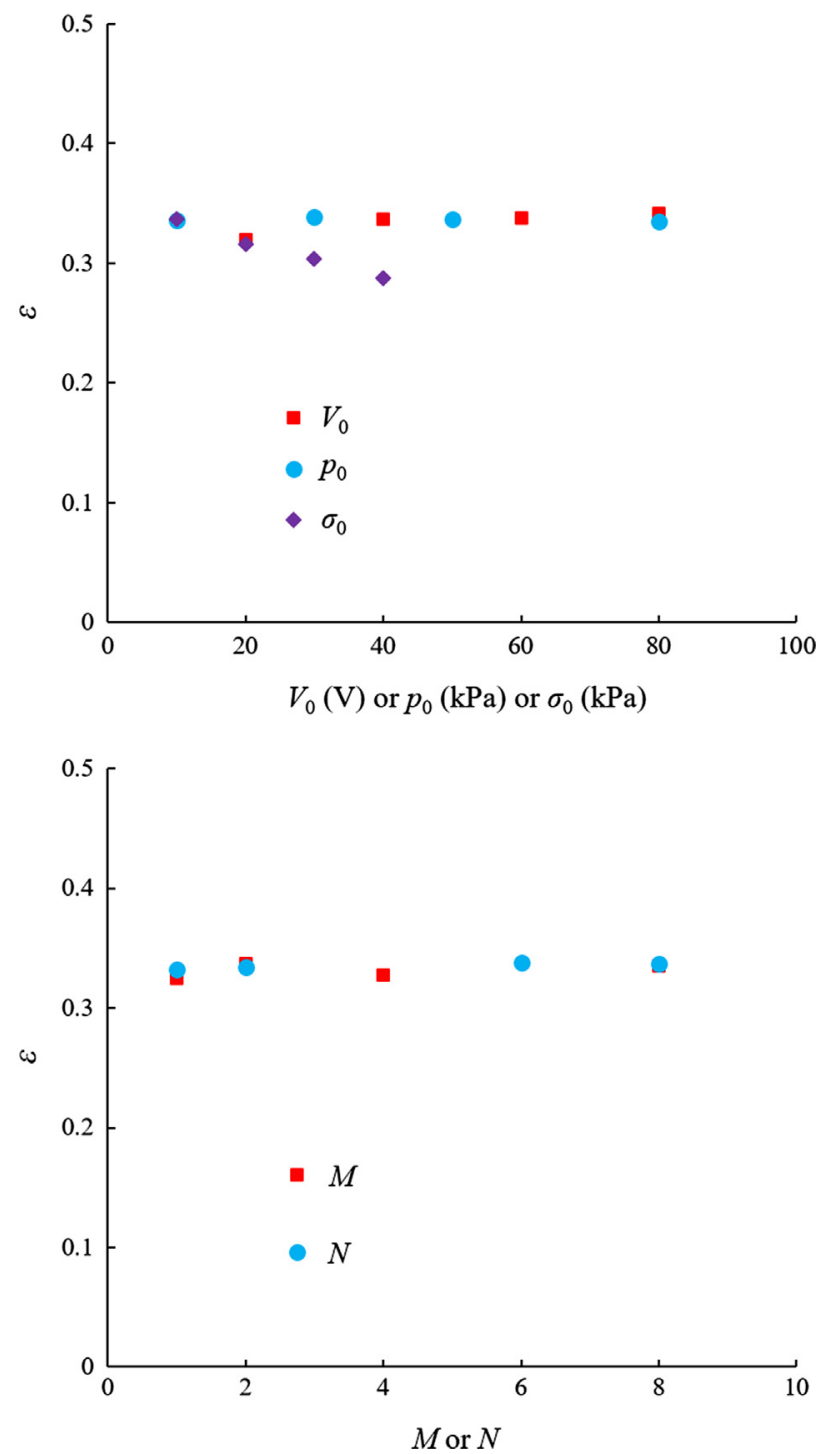

Fig. 5. Values of the weighted factor for different soil properties and electro-osmosis conditions. 
the range of $0.30-0.45$, and can be estimated relatively precisely according to the initial hydraulic conductivity $k_{\mathrm{h} 0}$, i.e., larger $\varepsilon$ for smaller $k_{\mathrm{ho}}$ and vice versa.

The effect of the weighted factor $\varepsilon$ is further shown in Fig. 6, which compares the excess pore water pressure at different depths $(z / H=0.1, z / H=0.5$ and $z / H=1.0)$ from the analytical solution and the numerical results respectively. Due to electro-osmosis, the excess pore water pressure in the model decreases from $50 \mathrm{kPa}$ to a negative value at the end of the consolidation process, which is about $-4.6 \mathrm{kPa}$ at $z / H=0.1,-23.2 \mathrm{kPa}$ at $z / H=0.5$ and $-46.8 \mathrm{kPa}$ at $z / H=1.0$. The development of $u$ is highly dependent on the value of $\varepsilon$. With the increase in $\varepsilon$ from 0 to $1.0, u$ increases during the electro-osmotic consolidation process, and $\varepsilon=0.33$ gives the best agreement with the numerical results for the examined conditions. Therefore, the value of $\varepsilon=0.33$ is used in the following analysis.

\subsection{Excess pore water pressure}

According to Eqs. (5) and (6), the higher the value of $M$ and $N$, the less sensitive of $k_{\mathrm{h}}$ and $k_{\mathrm{e}}$ to the change in void ratio, and when $M$ and $N$ approaches infinity, $k_{\mathrm{h}}$ and $k_{\mathrm{e}}$ are actually constant during the consolidation process. Therefore, in order to examine the effect of the non-linear variation of $k_{\mathrm{h}}$, the value of $N$ is set to be 100 , and the value of $M$ is set to be 100 to investigate the effect of the nonlinear variation of $k_{\mathrm{e}}$.

Fig. 7 shows the comparison of the analytical solutions and the numerical results at different depths, with $C_{\mathrm{c}}=0.2, N=100$ and $M$ varying from 0.5 to 8.0 . With the increase in $M$, the excess pore water pressure from Wan and Mitchell [15] remains constant, while the results from the analytical solution in this study and the numerical simulation decrease. For all the $M$ values analyzed here, the excess pore water pressure calculated from the analytical solution in this study agrees well with that from the numerical simulation, while the results from Wan and Mitchell [15] is smaller, especially at the bottom of the model. According to previous theories about electro-osmotic consolidation, the effects of $k_{\mathrm{h}}$ and $k_{\mathrm{e}}$ on the development of excess pore water pressure are different, specifically, a larger $k_{\mathrm{e}}$ results in a larger negative excess pore water pressure (under constant $k_{\mathrm{h}}$ ), while a larger $k_{\mathrm{h}}$ induces a smaller one (under constant $k_{\mathrm{e}}$ ). Because $k_{\mathrm{h}}$ gradually decreases during electro-osmotic consolidation, the calculated value of the ultimate excess pore water pressure in this study is larger than that from Wan and Mitchell [15]. With the increase in $M$, the effect of the non-linear variation of the hydraulic conductivity decreases and the difference between the calculated excess pore water pressure from this study and that from Wan and Mitchell [15] decreases.
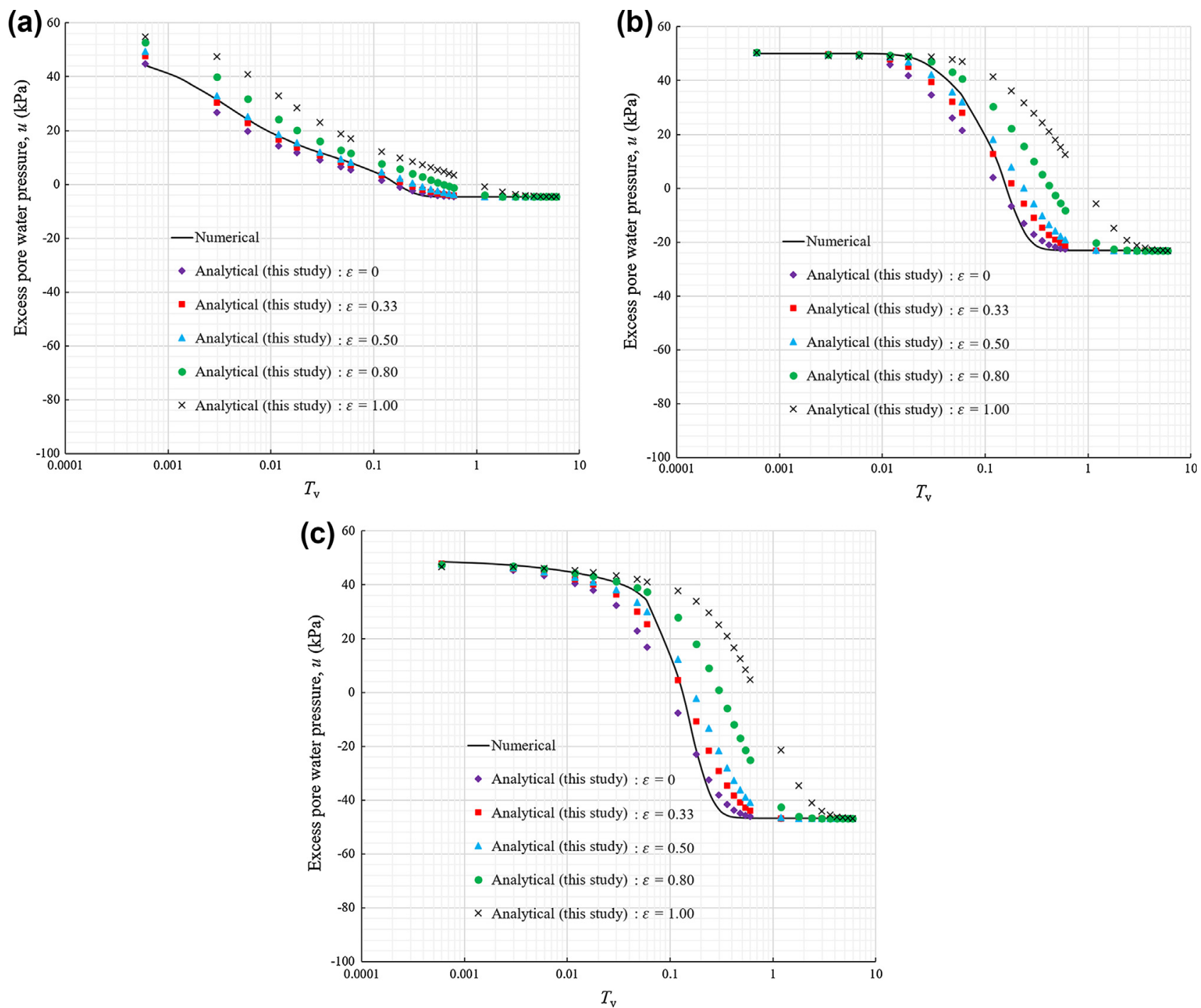

Fig. 6. Effect of the weighted factor on the development of the excess pore water pressure: (a) $z / H=0.1$; (b) $z / H=0.5$; and (c) $z / H=1.0$. 

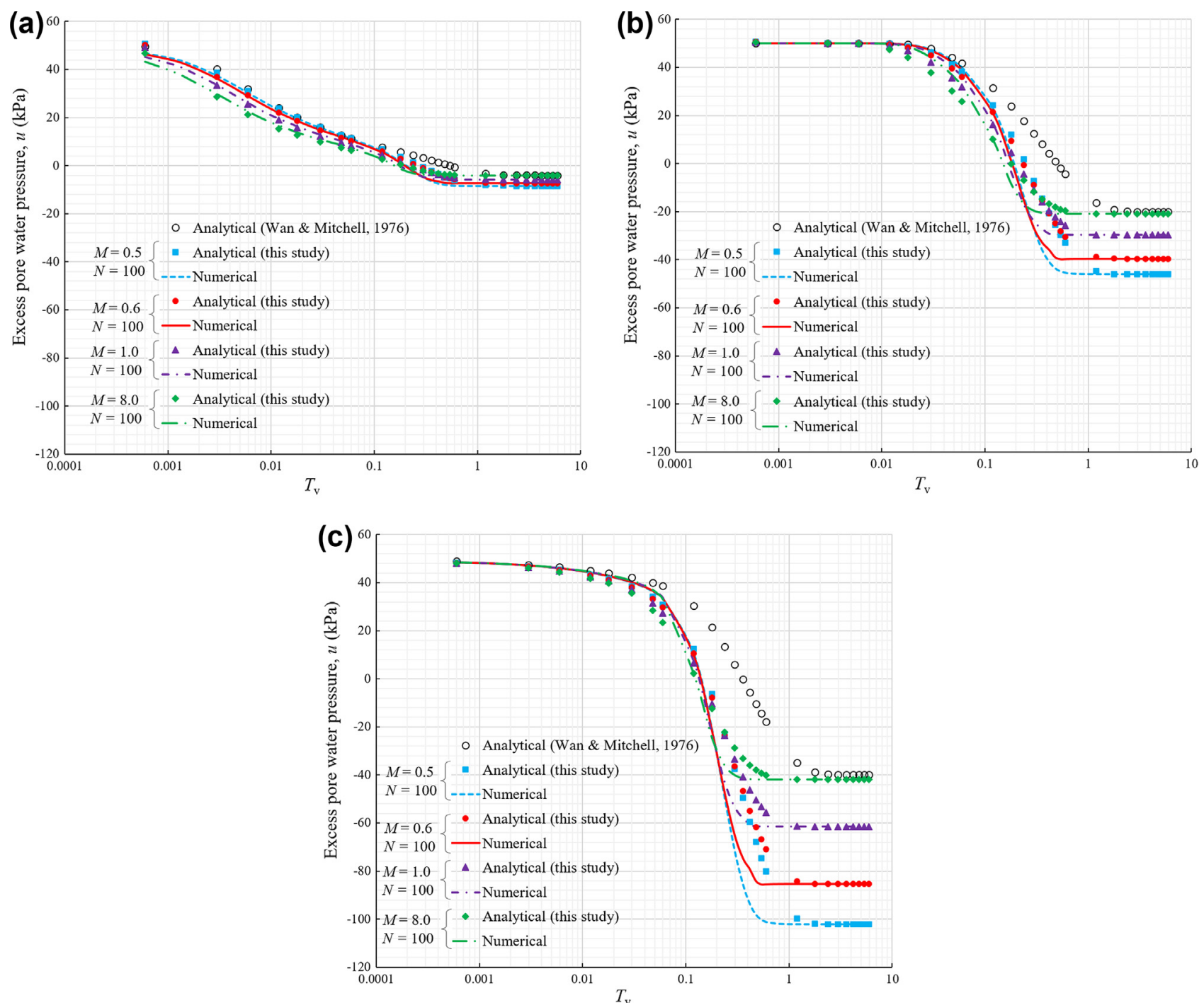

Fig. 7. Effect of the non-linear variation of hydraulic conductivity on the development of the excess pore water pressure: $(\mathrm{a}) z / H=0.1$; $(\mathrm{b}) z / H=0.5$; and $(\mathrm{c}) z / H=1.0$.

Fig. 8 illustrates the development of the excess pore water pressure with $C_{\mathrm{c}}=0.2, M=100$ and $N$ varying from 0.5 to 8.0 . The excess pore water pressure calculated from Wan and Mitchell [15] remains constant, while the results from the presented analytical solution and the numerical simulation increase with the increase in $N$. For all the $N$ values analyzed here, the results from the presented analytical solution in this study agree well with that from the numerical simulation. Since a larger $k_{\mathrm{e}}$ leads to a larger excess pore water pressure, the value of the ultimate pore water pressure in this study is smaller than that from Wan and Mitchell [15]. With the increase in $N$, the effect of the non-linear variation of the electro-osmosis conductivity decreases and the calculated excess pore water pressure increases.

The change in the coefficient of consolidation $C_{\mathrm{v}}$ during electroosmotic consolidation depends on the values of $C_{\mathrm{c}}$ and $M$. Lekha et al. [33] indicated that if $C_{\mathrm{c}}=M, C_{\mathrm{v}}$ remained constant, if $C_{\mathrm{c}}>M$, $C_{\mathrm{v}}$ decreased with the decrease in the void ratio, and if $C_{\mathrm{c}}<M, C_{\mathrm{v}}$ increased. For the cases examined here, $C_{\mathrm{c}}<M$, and therefore $C_{\mathrm{v}}$ increases during the consolidation process. As a result, the development of the excess pore water pressure calculated from the present analytical solution is faster than that from Wan and Mitchell [15] as shown in Figs. 7 and 8.

Fig. 9 displays the effect of $C_{\mathrm{c}}$ with $M=2.0$ and $N=8.0$. Since the change in $C_{\mathrm{c}}$ leads to the change in $C_{\mathrm{v}}$ and $T_{\mathrm{v}}, t$ is used as the horizontal ordinate instead of $T_{\mathrm{v}}$. With the increase in $C_{\mathrm{c}}$, the soil compressibility increases and $C_{\mathrm{v}}$ decreases, therefore the development of the excess pore water pressure becomes slower, both for the analytical solution in this study and that from Wan and Mitchell [15]. When the soil properties are assumed constant, the value of the ultimate negative excess pore water pressure is independent of $C_{\mathrm{c}}$, while when the non-linear variations of soil properties are considered, the value of the ultimate negative excess pore water pressure increases with the increase in $C_{\mathrm{c}}$. With a higher $C_{\mathrm{c}}$, the soil is more compressible and the changes in $k_{\mathrm{h}}$ and $k_{\mathrm{e}}$ are larger during electro-osmotic consolidation, which means that the effect of the non-linear variations of soil properties is more significant. According to Figs. 7 and 8 , the non-linear variation of $k_{\mathrm{h}}$ results in a larger value of the ultimate excess pore water pressure, while the nonlinear variation of $k_{\mathrm{e}}$ leads to a smaller one. For the given values of $k_{\mathrm{h}}, k_{\mathrm{e}}, M$ and $N$, the effect of the non-linear variation of $k_{\mathrm{h}}$ is more remarkable than that of $k_{\mathrm{e}}$. As a result, a larger value of the ultimate excess pore water pressure is obtained with a higher $C_{\mathrm{c}}$.

\subsection{Degree of consolidation}

The comparison of the degree of consolidation is displayed in Figs. 10-12. The effects of $M, N$ and $C_{\mathrm{c}}$ are analyzed, respectively. Similar to that of the excess pore water pressure, with the change 

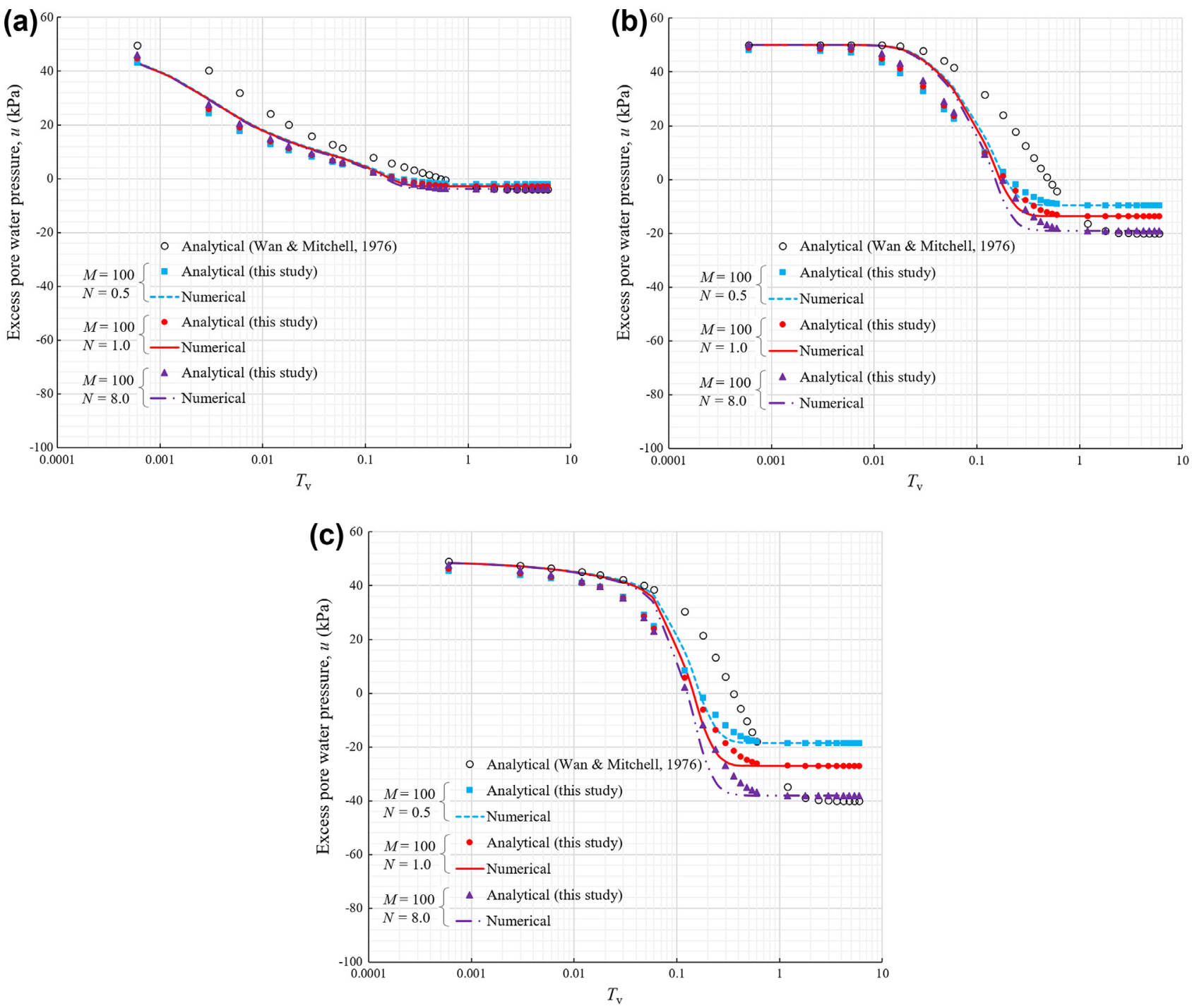

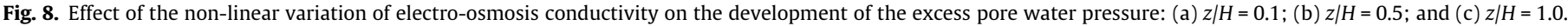

in $M$ and $N$, the degree of consolidation obtained from Wan and Mitchell [15] remains constant, while the results from the present analytical solution and the numerical simulation increase with the increase in $M$, and decrease with the increase in $N$. As mentioned before, the decrease in $k_{\mathrm{h}}$ during the consolidation process is smaller with a larger $M$, therefore the value of the ultimate excess pore water pressure is smaller and the coefficient of consolidation is larger. As a result, the degree of consolidation is larger for a larger $M$. Opposite to $k_{\mathrm{h}}$, the value of the ultimate excess pore water pressure is positively related to $k_{\mathrm{e}}$, and therefore is larger for a larger $N$, hence the degree of consolidation decreases with the increase in $N$.

According to the above analysis, the non-linear variation of $k_{\mathrm{h}}$ influences not only the excess pore water pressure but also the coefficient of consolidation, while the non-linear variation of $k_{\mathrm{e}}$ only affects the excess pore water pressure. Consequently, the impact of the non-linear variation of $k_{\mathrm{h}}$ is larger than that of $k_{\mathrm{e}}$, both for the excess pore water pressure and the degree of consolidation as shown in Figs. 7, 8, 10 and 11.

The increase in $C_{\mathrm{v}}$ during the consolidation process is neglected since the soil compressibility is assumed constant in the theory of Wan and Mitchell [15], therefore the degree of consolidation calcu- lated from Wan and Mitchell [15] is smaller than that from the present analytical solution and the numerical simulation (Figs. 10 and 11). The impact of $C_{\mathrm{c}}$ is further shown in Fig. 12. Compared to the results of Wan and Mitchell [15], the degree of consolidation obtained from the present analytical simulation is larger since $C_{\mathrm{v}}$ increases during the consolidation process when $C_{\mathrm{c}}<M$. With the increase in $C_{\mathrm{c}}, C_{\mathrm{v}}$ decreases and therefore the degree of consolidation decreases.

Figs. 7-9 illustrates that the distribution of the excess pore water pressure during electro-osmotic consolidation calculated from the present analytical solution agrees well with that from the numerical simulation, and Figs. 10-12 further indicates that the degree of consolidation can also be well predicted with the present analytical solution.

In the above analysis about the excess pore water pressure and the degree of consolidation, the values of $M$ and $N$ are set to change from 0.5 to 100 in order to analyze the impact of the non-linear variations of $k_{\mathrm{h}}$ and $k_{\mathrm{e}}$ respectively. In fact, according to previous studies, $k_{\mathrm{e}}$ is generally less sensitive to the change in void ratio compared to $k_{\mathrm{h}}[5,7,39,40]$. Therefore, the above-mentioned case of $M<N$ is more common in practical situation. 

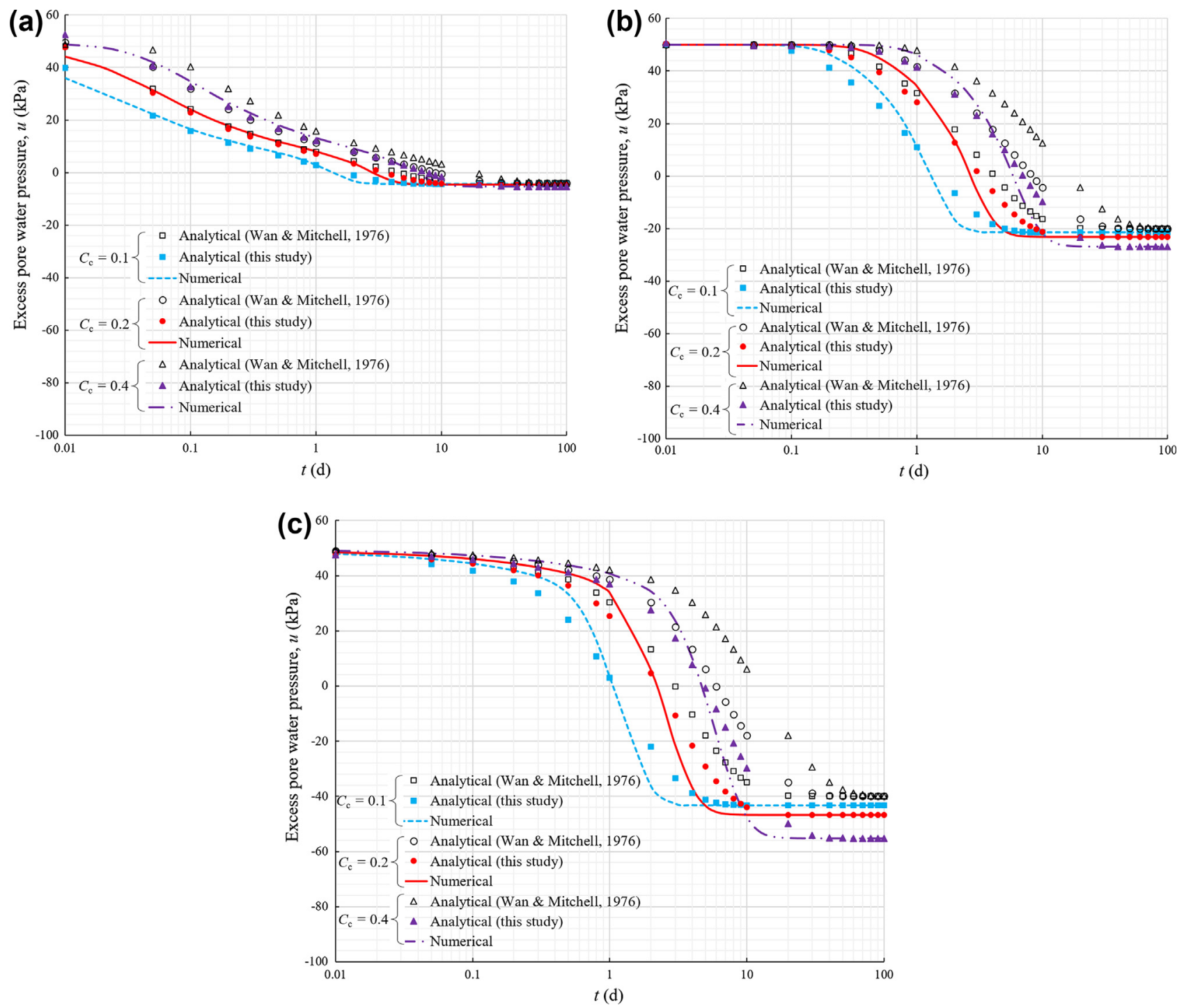

Fig. 9. Effect of the non-linear variation of soil compressibility on the development of the excess pore water pressure: $(\mathrm{a}) z / H=0.1$; $(\mathrm{b}) z / H=0.5$; and $(\mathrm{c}) z / H=1.0$.

\subsection{Ultimate excess pore water pressure}

Due to the introduction of $\varepsilon$ and the simplification of the governing equation from Eqs. (16)-(21), there is a slight deviation between the analytical solution and the numerical simulation as illustrated by Fig. 6. However, it is worth noting that the ultimate excess pore water pressure achieved after $T_{\mathrm{v}}=1$ is almost the same in the analytical solution and the numerical simulation, regardless of the value of $\varepsilon$. Figs. 7-9 further demonstrate that although the excess pore water pressure (absolute value) obtained from the proposed analytical solution is slightly different from the numerical simulation, the ultimate excess pore water pressure calculated from the two methods agrees quite well with each other. It seems that the ultimate excess pore water pressure calculated from Eq. (23) with $t$ approaching infinity is not affected by the introduction of the weighted average value for $\left(Q+C_{0} Z\right)$. In fact, the solution for the ultimate excess pore water pressure can be directly derived from the equilibrium of the hydraulic flow and electro-osmosis flow at the end of electro-osmotic consolidation process.

At equilibrium, the pore water flow in the soil mass is 0 , and the following equation can be obtained, $\frac{k_{\mathrm{h}}}{\gamma_{\mathrm{w}}} \cdot \frac{\partial u_{\mathrm{ult}}}{\partial z}+k_{\mathrm{e}} \cdot \frac{\partial V}{\partial z}=0$

in which $u_{\text {ult }}$ denotes the excess pore water pressure at the end of electro-osmotic consolidation.

Making the substitutions $W_{\mathrm{ult}}=u_{\mathrm{ult}} / p_{0}$ and $Z=z / H$,

$\frac{\partial W_{\mathrm{ult}}}{\partial Z}+\frac{k_{\mathrm{e}} \cdot \gamma_{\mathrm{w}}}{k_{\mathrm{h}} \cdot p_{0}} \cdot \frac{\partial V}{\partial Z}=0$

Substituting Eqs. (12) and (13) into Eq. (28), the following equation is obtained,

$\frac{\partial W_{\mathrm{ult}}}{\partial Z}=-\frac{k_{\mathrm{e} 0} \cdot \gamma_{\mathrm{w}}}{k_{\mathrm{h} 0} \cdot p_{0}} \cdot \frac{\partial V}{\partial Z} \cdot\left[\left(1+\frac{p_{0}}{\sigma_{\mathrm{p}}}\right) \cdot\left(1-\beta W_{\mathrm{ult}}\right)\right]^{C_{\mathrm{c}} / M-C_{\mathrm{c}} / N}$

Defining $Q_{\text {ult }}$ as,

$Q_{\text {ult }}=\left(1-\beta W_{\text {ult }}\right)^{1+C_{\mathrm{c}} / N-C_{\mathrm{c}} / M}$

Then Eq. (29) can be written as,

$\frac{\partial Q_{\mathrm{ult}}}{\partial Z}=\beta \cdot\left(1+\frac{C_{\mathrm{c}}}{N}-\frac{C_{\mathrm{c}}}{M}\right) \cdot\left(1+\frac{p_{0}}{\sigma_{\mathrm{p}}}\right)^{C_{\mathrm{c}} / M-C_{\mathrm{c}} / N} \cdot \frac{k_{\mathrm{e} 0} \cdot \gamma_{\mathrm{w}}}{k_{\mathrm{h} 0} \cdot p_{0}} \cdot \frac{\partial V}{\partial Z}=C_{0}$ 


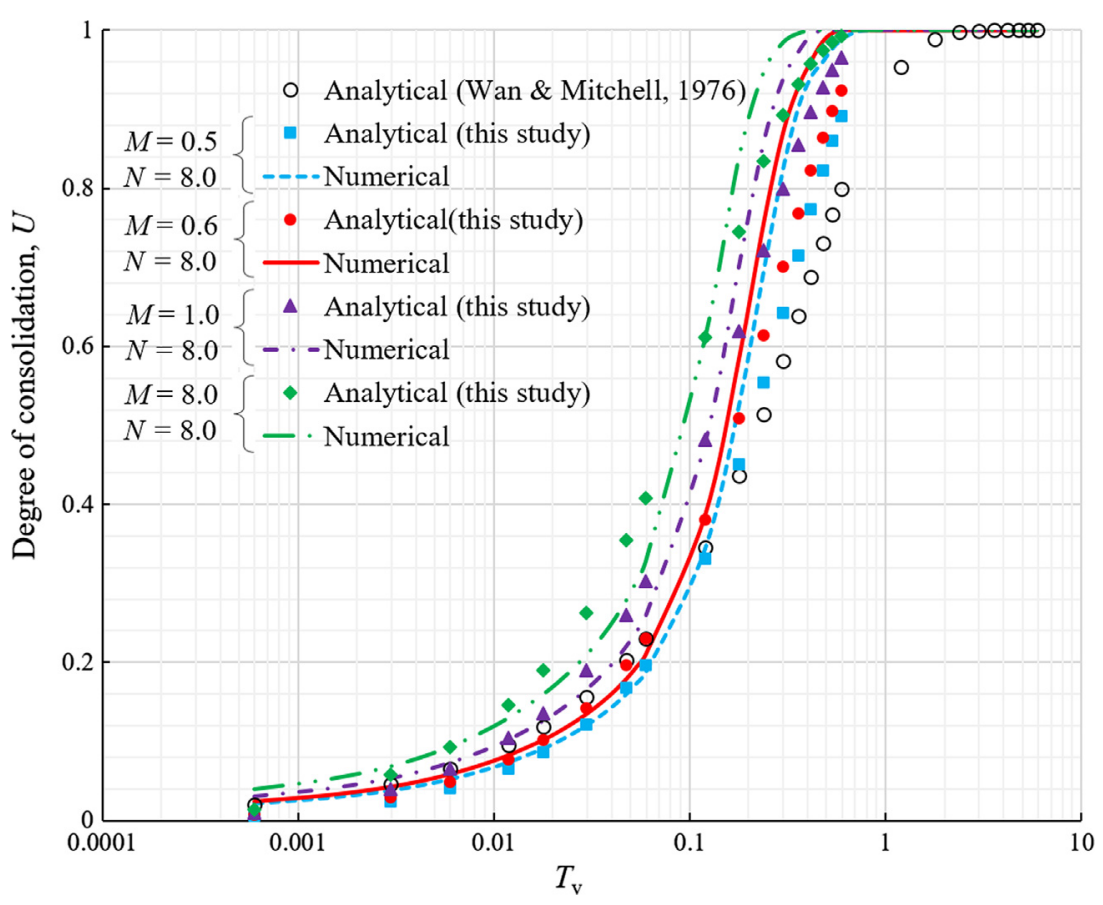

Fig. 10. Effect of the non-linear variation of hydraulic conductivity on the degree of consolidation.

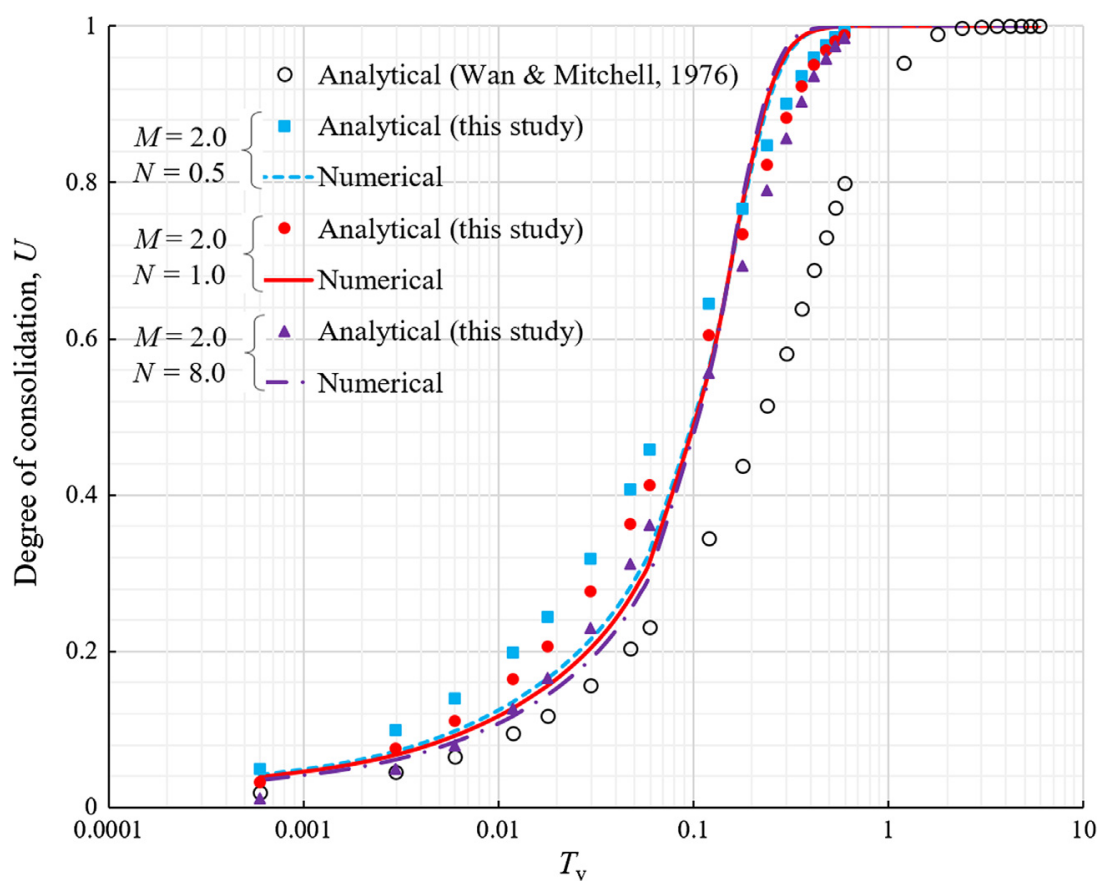

Fig. 11. Effect of the non-linear variation of electro-osmosis conductivity on the degree of consolidation.

Integrating Eq. (31) in $Z$ direction and considering the boundary condition that both the excess pore water pressure and voltage are 0 at the cathode, the solution for $u_{\text {ult }}$ can be obtained,

$u_{\mathrm{ult}}=\frac{p_{0}}{\beta} \cdot\left[1-\left(1+C_{0} \cdot Z\right)^{1 /\left(1+C_{\mathrm{c}} / N-C_{\mathrm{c}} / M\right)}\right]$

The above derivation indicates that the ultimate excess pore water pressure can be solved from Eq. (27) without any simplification or assumption. In fact, the solution for $u_{\mathrm{ult}}$ shown in Eq. (32) can also be obtained from the solution for $u$ (Eq. (23)) by making $t$ infinity.
According to Eq. (32), the ultimate excess pore water pressure (absolute value) decreases with the increase in $M$ and increases with the increase in $N$ (Figs. 7 and 8). The non-linear variation of $k_{\mathrm{h}}$ leads to a larger $u_{\mathrm{ult}}$, while the non-linear variation of $k_{\mathrm{e}}$ results in a smaller one. When both $M$ and $N$ approach infinity or $M=N$, the effect of the non-linear variations of $k_{\mathrm{h}}$ and $k_{\mathrm{e}}$ is eliminated or balanced by each other, and therefore the analytical solution for the ultimate excess pore water pressure degrades to the equation proposed by Esrig [14] and Wan and Mitchell [15],

$u_{\mathrm{ult}}=-\frac{k_{\mathrm{e} 0} \cdot \gamma_{\mathrm{w}}}{k_{\mathrm{h} 0}} \cdot V$ 


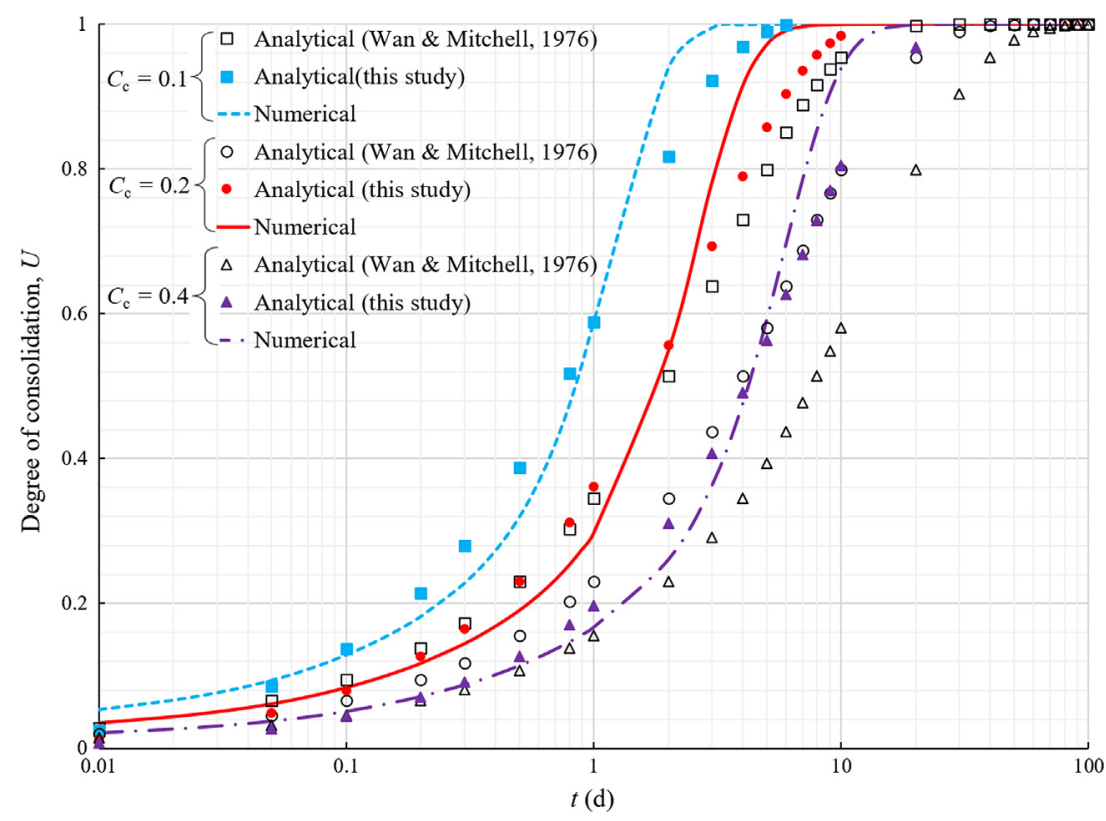

Fig. 12. Effect of the non-linear variation of soil compressibility on the degree of consolidation.

\section{Summary and conclusions}

In this study, the non-linear variations of soil compressibility, hydraulic conductivity and electro-osmosis conductivity during the consolidation process are analyzed through laboratory tests and incorporated in a 1D model for electro-osmotic consolidation. The analytical solutions for the excess pore water pressure and degree of consolidation are derived, and compared with the results from numerical simulations for verification. Both the analytical solutions and numerical results are further compared with previous solutions from Wan and Mitchell [15] to analyze the effect of the non-linear variations of soil properties.

With the decrease in void ratio, both the hydraulic conductivity and electro-osmosis conductivity decrease, and linear relationships between the logarithm of them and the void ratio are found from the experiment results. Two empirical formulas are further developed to account for the non-linear variations of the hydraulic conductivity and electro-osmosis conductivity.

The non-linear variations of soil properties show remarkable impact on the development of the excess pore water pressure and degree of consolidation during electro-osmotic consolidation. Specifically, the non-linear variation of hydraulic conductivity results in a larger excess pore water pressure, while the nonlinear variation of electro-osmosis conductivity leads to a smaller one. The more sensitive of hydraulic and electro-osmosis conductivities to the change in void ratio, the more significant the impact they show. With the increase in the initial soil compressibility, the development of the excess pore water pressure becomes slower, and the impact of the nonlinear variation of the hydraulic and electro-osmosis conductivities becomes more remarkable since the changes in the void ratio are larger with higher compressibility.

The coefficient of consolidation is related to soil compressibility and hydraulic conductivity. When the decrease in soil compressibility is larger than the decrease in hydraulic conductivity, the coefficient of consolidation increases during the consolidation process, therefore the degree of consolidation calculated from the present analytical solution is larger than that from previous solutions with constant soil properties.

The present analytical results agree well with the numerical results, both for the excess pore water pressure and the degree of consolidation. Compared to the previous analytical solutions, the newly proposed analytical solutions give more accurate predictions, and can be used to analyze the consolidation behavior of soil treated by electro-osmotic consolidation.

\section{Acknowledgments}

Financial support from the National Natural Science Foundation of China (Project No. 51579132, 51323014), the Ministry of Education (Project No. THZ-02-2), and the China Postdoctoral Science Foundation (Grant No. 2015M581104) are gratefully acknowledged.

\section{Appendix A. Details of the derivation of the 1D model for electro-osmotic consolidation with variable compressibility, hydraulic conductivity and electro-osmosis conductivity}

The governing equation and the boundary conditions and the initial condition can be expressed as,

$$
\left\{\begin{array}{l}
\frac{\partial Q}{\partial T_{\mathrm{e}}}=\frac{\partial^{2} Q}{\partial Z^{2}}+\alpha \cdot \frac{\partial Q}{\partial Z} \cdot \frac{\partial Q}{\partial Z}+\theta \cdot \frac{\partial Q}{\partial Z} \\
Z=0, u=0 \Rightarrow Q=1 \\
Z=1, \frac{k_{\mathrm{h}}}{\gamma_{\mathrm{w}}} \frac{\partial u}{\partial z}+k_{\mathrm{e}} \frac{\partial V}{\partial z}=0 \Rightarrow \frac{\partial Q}{\partial Z}=0 \\
t=0, u=p_{0} \Rightarrow Q=(1-\beta)^{1+C_{\mathrm{c}} / N-C_{\mathrm{c}} / M}-C_{0} \cdot Z
\end{array}\right.
$$

Defining a new variable $R$ as,

$R=e^{\alpha \cdot(Q-1)}-1$

Substituting Eq. (A2) into Eq. (A1) and the following equation can be obtained,

$$
\left\{\begin{array}{l}
\frac{\partial R}{\partial T_{e}}=\frac{\partial^{2} R}{\partial Z^{2}}+\theta \cdot \frac{\partial R}{\partial Z} \\
Z=0, R=0 \\
Z=1, \frac{\partial R}{\partial Z}=0 \\
t=0, R=e^{\alpha\left[\left(1+\frac{p_{0}}{\sigma_{0}}\right)^{C_{C} / M-C_{C} / N-1}-C_{0} \cdot Z-1\right]}-1=e^{\alpha\left[\left(1+\frac{p_{0}}{\sigma_{0}}\right)^{C_{C} / M-C_{C} / N-1}-1\right]} \cdot e^{-\alpha C_{0} Z-1}
\end{array}\right.
$$

Using the separating method and $R$ can be expressed as,

$R\left(Z, T_{\mathrm{e}}\right)=T\left(T_{\mathrm{e}}\right) \cdot \mathrm{Z}(Z)$ 
Substituting Eq. (A4) into the governing equation in Eq. (A3),

$T^{\prime}\left(T_{\mathrm{e}}\right) Z(Z)=T\left(T_{\mathrm{e}}\right) Z^{\prime \prime}(Z)+\theta T\left(T_{\mathrm{e}}\right) Z^{\prime}(Z) \Rightarrow \frac{T^{\prime}\left(T_{\mathrm{e}}\right)}{T\left(T_{\mathrm{e}}\right)}=\frac{Z^{\prime \prime}(Z)+\theta \cdot Z^{\prime}(Z)}{Z(Z)}$

$=-\lambda \Rightarrow\left\{\begin{array}{l}T^{\prime}\left(T_{\mathrm{e}}\right)+\lambda T\left(T_{\mathrm{e}}\right)=0 \\ Z^{\prime \prime}(Z)+\theta \cdot Z^{\prime}(Z)+\lambda Z(Z)=0\end{array}\right.$

$T\left(T_{\mathrm{e}}\right)$ can be solved as,

$T\left(T_{\mathrm{e}}\right)=D_{n} e^{-\lambda T_{\mathrm{e}}}$

$Z(Z)$ can be solved as,

$$
\begin{aligned}
& Z(Z)=e^{-\frac{1}{2} \theta Z}\left[F_{1} \sin \left(\frac{1}{2} \xi Z\right)+F_{2} \cos \left(\frac{1}{2} \xi Z\right)\right] \\
& \xi^{2}=4 \lambda-\theta^{2}
\end{aligned}
$$

Considering the boundary conditions, $F_{2}=0$ and $\xi$ should satisfy the following,

$\tan \left(\frac{\xi}{2}\right)=\frac{\xi}{\theta}$

The solutions for $\xi$ can be solved from Eq. (A8) and mark them as $\xi_{n}(n=1,2,3,4,5 \ldots)$.

Therefore, $Z(Z)$ can be further derived as,

$Z(Z)=\sum_{n=1}^{\infty} e^{-\frac{1}{2} \theta Z} \cdot F_{1 n} \sin \left(\frac{1}{2} \xi_{n} Z\right)$

Then,

$R=\sum_{n=1}^{\infty} G_{n} e^{-\lambda_{n} T_{e}} \cdot e^{-\frac{1}{2} \theta Z} \cdot \sin \left(\frac{1}{2} \xi_{n} Z\right)$

$\frac{\xi_{n}^{2}+\theta^{2}}{4}=\lambda_{n}$

According to the initial condition, $G_{n}$ can be calculated as,

$$
\begin{aligned}
G_{n}= & \frac{I \cdot \frac{2}{\xi_{n}}-I \cdot e^{J} \cdot \frac{2}{\xi_{n}} \cdot \frac{\theta}{\sqrt{\theta^{2}+\xi_{n}^{2}}}+I \cdot J \cdot e^{J} \cdot \frac{4}{\xi_{n}^{2}} \cdot \frac{\xi_{n}}{\sqrt{\theta^{2}+\xi_{n}^{2}}}}{\left(1+J^{2} \cdot \frac{4}{\xi_{n}^{2}}\right) \cdot\left(\frac{1}{2}-\frac{\theta}{\theta^{2}+\xi_{n}^{2}}\right)} \\
& -\frac{\frac{2}{\xi_{n}}-e^{\frac{1}{2} \theta} \cdot \frac{2}{\xi_{n}} \cdot \frac{\theta}{\sqrt{\theta^{2}+\xi_{n}^{2}}}+\frac{1}{2} \theta \cdot e^{\frac{1}{2} \theta} \cdot \frac{4}{\xi_{n}^{2}} \cdot \frac{\xi_{n}}{\sqrt{\theta^{2}+\xi_{n}^{2}}}}{\left(1+\frac{\theta^{2}}{\xi_{n}^{2}}\right) \cdot\left(\frac{1}{2}-\frac{\theta}{\theta^{2}+\xi_{n}^{2}}\right)}
\end{aligned}
$$

where

$I=e^{\alpha\left[\left(1+\frac{p_{0}}{\sigma_{0}}\right)^{C_{\mathrm{c}} / M-C_{\mathrm{c}} / N-1}-1\right]} \quad J=\frac{1}{2} \theta-\alpha C_{0}$

And $Q$ can be expressed as,

$Q=\frac{1}{\alpha} \ln \left[\sum_{n=1}^{\infty} G_{n} e^{-\lambda_{n} T_{e}} \cdot e^{-\frac{1}{2} \theta Z} \cdot \sin \left(\frac{1}{2} \xi_{n} Z\right)+1\right]+1$

Then, the excess pore water pressure $u$ can be derived as,

$u=\frac{p_{0}}{\beta}-\frac{p_{0}}{\beta} \cdot\left\{\frac{1}{\alpha} \ln \left[\sum_{n=1}^{\infty} G_{n} e^{-\lambda_{n} T_{\mathrm{e}}} \cdot e^{-\frac{1}{2} \theta Z} \cdot \sin \left(\frac{1}{2} \xi_{n} Z\right)+1\right]+1+C_{0} Z\right\}^{1 /\left(1+C_{\mathrm{c}} / N-C_{\mathrm{c}} / M\right)}$

\section{References}

[1] Casagrande L. Stabilization of soils by means of electro-osmotic state-of-art. J Boston Civ Eng ASCE 1983;69(3):255-302.

[2] Lo KY, Ho KS. The effects of electroosmotic field treatment on the soil properties of a soft sensitive clay. Can Geotech J 1991;28(6):763-70.

[3] Micic S, Shang JQ, Lo KY, Lee YN, Lee SW. Electrokinetic strengthening of a marine sediment using intermittent current. Can Geotech J 2001;38 (2):287-302.

[4] Burnotte F, Lefebvre G, Grondin G. A case record of electro-osmotic consolidation of soft clay with improved soil-electrode contact. Can Geotech J 2004;41:1038-53.

[5] Mitchell JK, Soga K. Fundamentals of soil behavior. 3rd ed. New York: John Wiley \& Sons, Inc; 2005.

[6] Glendinning S, Lamont-Black J, Jones CJFP, Hall J. Treatment of lagooned sewage sludge in situ using electrokinetic geosynthetics. Geosynthetics Int 2008;15(3):192-204.
[7] Hu LM, Wu WL, Wu H. Numerical model of electro-osmotic consolidation in clay. Géotechnique 2012;62(6):537-41.

[8] Deng A, Zhou YD. Modeling electroosmosis and surcharge preloading consolidation. I: Model formulation. J Geotech Geoenviron Eng 2015:04015093.

[9] Wu H, Hu LM, Zhang L, Wen QB. Transport and exchange behavior of ions in bentonite during electro-osmotic consolidation. Clays Clay Miner 2015;63 (5):395-403.

[10] Yuan J, Hicks MA. Numerical analysis of electro-osmosis consolidation: a case study. Geotech Lett 2015;5(3):147-52.

[11] Lefebvre G, Burnotte F. Improvements of electroosmotic consolidation of soft clays by minimizing power loss at electrodes. Can Geotech J 2002;39 (2):399-408.

[12] Jeyakanthan V, Gnanendran CT. Elastoplastic numerical approach for predicting the electro-osmotic consolidation behaviour of soft clays. Can Geotech J 2013;50(12):1219-35.

[13] Wu H, Hu LM, Wen QB. Electro-osmotic enhancement of bentonite with reactive and inert electrodes. Appl Clay Sci 2015;111(7):76-82.

[14] Esrig MI. Pore pressures, consolidation and electro-kinetics. J Soil Mech Found Eng Div, ASCE 1968;94(7):899-921.

[15] Wan TY, Mitchell JK. Electro-osmotic consolidation of soils. J Geotech Eng Div, ASCE 1976;102(5):473-91.

[16] Shang JQ. Electro-osmotic enhanced preloading consolidation via vertical drains. Can Geotech J 1998;35(3):491-9.

[17] Li Y, Gong XN, Lu MM, Guo B. Coupling consolidation theory under combined action of load and electro-osmosis. Chin J Geotech Eng 2010;32(1):77-81 [in Chinese].

[18] Wang LJ, Liu SH, Wang ZJ, Zhang K. A consolidation theory for one-dimensional large deformation problems under combined action of load and electroosmosis. Eng Mech 2013;30(12):91-8 [in Chinese].

[19] $\mathrm{Wu} \mathrm{H}$, Hu LM. Analytical solution for axisymmetric electro-osmotic consolidation. Géotechnique 2013;63(12):1074-9.

[20] Wang J, Fu HT, Cai YQ Zeng FJ, Shen JJ. Analyses of one dimensional electroosmotic consolidation theory and test of soft clay under linear load. Chin J Rock Mech Eng 2014;33(1):179-88 (in Chinese).

[21] Xu W, Liu SH, Wang LJ, Wang JB. Analytical theory of soft ground consolidation under vacuum preloading combined with electro-osmosis. J Hohai Univ (Nat Sci) 2011;30(2):169-75 [in Chinese].

[22] Su J, Wang Z. The two-dimensional consolidation theory of electro-osmosis. Géotechnique 2003;53(8):759-63.

[23] Bjerrum L, Moum J, Eide O. Application of electroosmosis to a foundation problem in Norwegian quick clay. Géotechnique 1967;17:214-35.

[24] Jeyakanthan V, Gnanendran CT, Lo SCR. Laboratory assessment of electroosmotic stabilization of soft clay. Can Geotech J 2011;48(12):1788-802.

[25] Zhou YD, Deng A, Wang C. Finite-difference model for one-dimensional electro-osmotic consolidation. Comput Geotech 2013;54:152-65.

[26] Yuan J. Hicks MA. Large deformation elastic electro-osmosis consolidation of clays. Comput Geotech 2013;54:60-8.

[27] Hu LM, Wu H. Mathematical model of electro-osmotic consolidation for soft ground improvement. Géotechnique 2014;64(2):155-64.

[28] Wu H, Hu LM. Microfabric change of electro-osmotic stabilized bentonite. Appl Clay Sci 2014;101(11):503-9.

[29] Davis FH, Raymond GP. A non-linear theory of consolidation. Géotechnique 1965;15(2):161-73.

[30] Gibson RE, England GL, Hussey MJL. The theory of one-dimensional consolidation of saturated clays, 1 . Finite nonlinear consolidation of thin Homogeneous layers. Géotechnique 1967;17(3):261-73.

[31] Poskitt TJ. The consolidation of saturated clay with variable permeability and compressibility. Géotechnique 1969;19(2):234-52.

[32] Xie KH, Zheng H, Leo CJ. An analytical theory for 1-D nonlinear large strain consolidation of soft clay. Chin J Geotech Eng 2002;24(6):680-4 [in Chinese].

[33] Lekha KR, Krishnaswamy NR, Basak P. Consolidation of clays for variable permeability and compressibility. J Geotech Geoenviron Eng 2003;129 (11):1001-9.

[34] Indraratna B, Rujikiatkamjorn C, Sathananthan L. Radial consolidation of clay using compressibility indices and varying horizontal permeability. Can Geotech J 2005;42(5):1330-41.

[35] Geng XY, Xu CJ, Cai YQ. Non-linear consolidation analysis of soil with variable compressibility and permeability under cyclic loadings. Int J Numer Anal Meth Geomech 2006;30:803-21.

[36] Cai YQ, Geng XY, Xu CJ. Solution of one-dimensional finite-strain consolidation of soil with variable compressibility under cyclic loadings. Comput Geotech 2007;34(1):31-40.

[37] Walker R, Indraratna B, Rujikiatkamjorn C. Vertical drain consolidation with non-Darcian flow and void-ratio-dependent compressibility and permeability. Géotechnique 2012;62(11):985-97.

[38] Abuel-Naga H, Pender M. Modified Terzaghi consolidation curves with effective stress-dependent coefficient of consolidation. Géotech Lett 2012;2:43-8.

[39] Meegoda NJ, King IP, Arulanandan K. An expression for permeability of anisotropic granular media. Int J Numer Anal Meth Geomech 1989;13 (6):575-98.

[40] Wu WL. Theoretical model and numerical simulation of electro-osmotic consolidation on soft clay MS thesis. Beijing, China: Tsinghua University; 2009. 